\title{
Biodegradable and Water Resistant Poly(vinyl) Alcohol (PVA)/Starch (ST)/Glycerol (GL)/Halloysite Nanotube (HNT) Nanocomposite Films for Sustainable Food Packaging
}

\author{
Zainab Waheed Abdullah ${ }^{1,2}$ and Yu Dong ${ }^{1 *}$ \\ ${ }^{1}$ School of Civil and Mechanical Engineering, Curtin University, Perth, WA, Australia, ${ }^{2}$ Technical Engineering \\ College-Baghdad, Middle Technical University, Baghdad, Iraq
}

OPEN ACCESS

Edited by:

Andrea Dorigato,

University of Trento, Italy

Reviewed by:

Filippo Parisi,

University of Palermo, Italy

Marina Massaro,

University of Palermo, Italy

Giuseppe Lazzara,

University of Palermo, Italy

Pooria Pasbakhsh,

Monash University Malaysia, Malaysia

*Correspondence:

Yu Dong

Y.Dong@curtin.edu.au

Specialty section:

This article was submitted to

Polymeric and Composite Materials,

a section of the journal

Frontiers in Materials

Received: 01 February 2019

Accepted: 20 March 2019

Published: 17 April 2019

Citation:

Abdullah ZW and Dong Y (2019) Biodegradable and Water Resistant

Poly(vinyl) Alcohol (PVA)/Starch

(ST)/Glycerol (GL)/Halloysite

Nanotube (HNT) Nanocomposite

Films for Sustainable Food Packaging.

Front. Mater. 6:58.

doi: 10.3389/fmats.2019.00058
As a novel biodegradable material, poly (vinyl) alcohol (PVA)/starch (ST)/ glycerol (GL)/ halloysite nanotube (HNT) nanocomposite films were prepared by solution casting at the HNT contents of $0.25,0.5,1,3$, and $5 \mathrm{wt} \%$. Water absorption capacity and water solubility of nanocomposite films were decreased remarkably by 44.24 and $48.05 \%$, respectively, with increasing the HNT content from 0 to 5 wt\% when compared with those of biopolymer matrices. Moreover, the water contact angle of nanocomposite films increased by $21.36^{\circ}$ with the incorporation of HNTs. The presence of HNTs appeared to reduce the overall migration rates for PVA/ST/GL/HNT nanocomposite films when interacting with either hydrophilic or lipophilic food simulants. However, the migration rates of HNTs alone were enhanced with increasing the HNT content in hydrophilic, lipophilic, and acidic food simulants. On the other hand, the biodegradation rate and light transmittance of nanocomposite films were reduced linearly by 18.56 and $26.90 \%$ with increasing the HNT content from 0 to 5 wt\%. Overall, novel PVAST/GL/HNT nanocomposite films in this study offer highly competitive materials with excellent water resistance, good biodegradability, and acceptable transparency to be potentially used for sustainable food packaging particularly targeting lipophilic and acidic foodstuffs.

Keywords: polymer blends, nanocomposites, water resistance, migration rate, biodegradability

\section{INTRODUCTION}

Petro-based polymers generally possess good mechanical, thermal and barrier properties with easy processability and relatively low cost, which makes them widely used in different industrial sectors such as construction and building, appliances, and material packaging (Siracusa et al., 2008; Sam et al., 2016; Abdullah et al., 2017). Nevertheless, it is evident that plastic wastes in $\sim 6,300$ million metric tons were generated worldwide in 2015, and if this production rate continues without effective control it will be increased up to 12,000 million metric tons of plastic wastes by 2050 (Geyer et al., 2017). Non-degradable plastic wastes can be eliminated by recycling, landfilling, and incineration resulting in high processing cost and increasing global warming (Ray and Bousmina, 2005; Shah et al., 2008). Consequently, the 
replacement of petro-based polymers with biopolymers becomes a suitable solution to tackle more severe environmental issues. Unfortunately, biopolymers have typical material demerits including high water/gas permeability, brittleness, and poor stability during processing as well as low heat resistance, so blending with other polymers and/or reinforcing with nanofillers can overcome these limitations (Sorrentino et al., 2007; Aslam et al., 2018).

Polyvinyl alcohol (PVA) is a synthetic water-soluble biopolymer, which possesses good mechanical and thermal properties as well as good transparency and resistance to oxygen permeation. Nonetheless, it has low degradation rates in some environments such as in soil along with relatively high cost and poor water resistance owing to the presence of hydroxyl groups in repeating units of PVA (Gupta et al., 2013; Gaaz et al., 2015; Lim et al., 2015; Aslam et al., 2018). Blending PVA with starch (ST) gives rise to the high improvement of biodegradability and cost reduction (Abdullah et al., 2017). ST is a completely biodegradable polymer in soil and compost, which is abundant as a spare storage in plants with non-toxic and relatively low-cost features. However, it is hard to process due to the high brittleness and limited flexibility (Avella et al., 2005; Tang et al., 2008; Jolanta et al., 2018). It is a semicrystalline polymer consisting of amylose and amylopectin at different ratios depending on plant sources. Amylose is a linear polymer in which glucopyranosyl repeating units are linked by $\alpha(1-4)$ linkages while the amylopectin is the branched counterpart with $\alpha(1-4)$ linked backbone and $\alpha$ (1-6) linked branches (Avella et al., 2005, Sam et al., 2016). Plasticized PVA/ST blends have been well-utilized since 1980s (Liu et al., 1999; Tang and Alavi, 2011). Such blends belong to a widespread material system used in numerous applications such as biomedical engineering and material packaging (Tang and Alavi, 2011; Luo et al., 2012; Tanase et al., 2015; Wang et al., 2015; Zanela et al., 2015). Glycerol (GL) is one of the most popular plasticisers mixed with PVA/ST blends due to their close solubility parameters, which are 22.50, 23.40, and 21.10 $\mathrm{MPa}^{1 / 2}$ for PVA, ST, and GL, respectively (Rahman et al., 2010). Many hydroxyl groups in Plasticized PVA/ST blends yield weak water resistance. To overcome this drawback, it is essential to reinforce such blends with applicable nanofillers to improve not only mechanical and thermal properties but also their barrier properties (Mensitieri et al., 2011; Wang et al., 2015). For instance, Tian et al. (2017) found the water absorption capacity $\left(W_{a}\right)$ of plasticized PVA/ST blend films was reduced by about $20 \%$ with the inclusion of 25 wt $\%$ montmorillonite (MMT) nanoclays. Similarly, Noshirvani et al. (2016) showed that the water solubility $\left(W_{s}\right)$ and water vapor permeability $(W V P)$ of plasticized PVA/ST/Cloisite- $\mathrm{Na}^{+}$MMT dropped by 50.81 and $16.46 \%$, respectively, with increasing the nanofiller content from 0 to $7 \mathrm{wt} \%$ due to tortuous paths generated within nanocomposite films. Metal oxides can be employed to reinforce plasticized PVA/ST blends as well. For instance, nano-silicon dioxide $\left(\mathrm{SiO}_{2}\right)$ was used by Tang et al. (2008) to improve mechanical properties and water resistance of plasticized PVA/ST blend films. Moreover, Akhavan et al. (2017) reported that the $W_{a}$ of plasticized PVA/ST blend films was reduced by $62 \%$ with the incorporation of $0.50 \mathrm{wt} \%$ nano-zinc oxide
( $\mathrm{ZnO})$. In addition, cellulose nanocrystals (CNCs) were also used by Noshirvani et al. (2016) to reinforce plasticized PVA/ST blend films. Water resistance results demonstrated that the $W_{S}$ and WVP of nanocomposites diminished by 25.19 and $4.85 \%$, respectively, with increasing the $\mathrm{CNC}$ content from 0 to $7 \mathrm{wt} \%$. Similarly, (Guimarães et al., 2015) found that the $W_{a}$ and WVP of plasticized PVA/ST/bamboo nanofibril nanocomposite films were decreased by 30 and $20 \%$, respectively, at the nanofiller content of $6.50 \mathrm{wt} \%$ when compared with those of plasticized PVA/ST blend films alone.

Halloysite nanotubes (HNTs) are a good nanofiller candidate to reinforce biopolymer blends because of their inherently good mechanical and thermal properties (Gaaz et al., 2017; Makaremi et al., 2017). To our best knowledge, HNTs as typical nanofillers have rarely been used to reinforce PVA/ST/GL blends despite their implementation in other bionanocomposite systems such as ST/HNT nanocomposites (Xie et al., 2011; He et al., 2012; Schmitt et al., 2015; Ren et al., 2018), PVA/HNT nanocomposites (Liu et al., 2007; Zhou et al., 2010; Qiu and Netravali, 2013; Fujii et al., 2014; Swapna et al., 2015), PVA/chitosan/HNT nanocomposites (Ali, 2016), soluble soybean polysaccharide (SSPS)/HNT nanocomposites (Alipoormazandarani et al., 2015), Pectin/HNT nanocomposites (Makaremi et al., 2017) and polylactic acid (PLA)/HNT nanocomposites (Dong et al., 2015; Castro-Aguirre et al., 2018; Chow et al., 2018). HNTs are naturally formed tubular nanoclays with a chemical formula $\mathrm{Al}_{2}(\mathrm{OH})_{4} \mathrm{Si}_{2} \mathrm{O}_{5} \cdot n \mathrm{H}_{2} \mathrm{O}$. Such a hollow tubular structure for HNTs is derived from warping octahedral and tetrahedral sheets in 1:1-layer clays (also called 1:1 phyllosilicate) with a lower number of hydroxyl groups on their outer surfaces to improve the HNT dispersion within polymer matrices (Gaaz et al., 2015). As compared with other tubular morphological structures of nanofillers like carbon nanotubes (CNTs), HNTs are cheap, widely available, and easily dispersed (Tully et al., 2015; Zhang et al., 2016). Moreover, it is considered as a non-toxic material mainly used for drug delivery in medical applications (Khoo et al., 2011; Rawtani and Agrewal, 2012; Salam et al., 2015; Yuan et al., 2015), and further for food packaging applications (Biddecia et al., 2016; Makaremi et al., 2017; Lee et al., 2018). Consequently, HNTs were used in this study as natural reinforcements for sustainable PVA/ST/GL/HNT nanocomposite films to improve their water resistance such as $W_{a}, W_{s}$ and water contact angle as their mechanical and thermal properties were improved previously (Abdullah and Dong, 2017) when compared with those of PVA/ST/GL blend matrices.

When using nanocomposite materials for food packaging applications, the migration rate of nanocomposite constituents like nanofillers to foodstuffs should be seriously considered due to the food safety issue (Simon et al., 2008; Gressler et al., 2018). The overall migration rate and migration rate of nanofillers are studied widely for packaging materials based on petro-based nanocomposites such as low density polyethylene (LDPE) nanocomposites with different types of nanofillers like nanosilver (Hannon et al., 2016), nanocarbon black (Bott et al., 2014b), nanoclays (Echegoyen et al., 2016), and nanotitanium nitride (Bott et al., 2014a). PLA nanocomposites are also of a 
particular concern in migration studies of bionanocomposite systems reinforced with different nanofillers such as sliver-based modified MMT nanoclays (Busolo et al., 2010), Cloisite nanoclays (Schmidt et al., 2009), CNCs (Fortunati et al., 2012), multiwalled CNTs (Velichkova et al., 2017). But very limited migration studies have been investigated based on other biopolymers like PVA and ST for potential material packaging applications. Avella et al. (2005) evaluated the migration rate of MMT nanoclays from ST/ 4 wt $\%$ MMT nanocomposite films in contact with lettuce and spinach. In a similar manner, MauricioIglesias et al. (2010) found different quantities of aluminum ions $\left(\mathrm{Al}^{+}\right)$and silicon ions $\left(\mathrm{Si}^{+}\right)$in food simulants owing to the migration of MMT nanoclays from wheat-gluten/MMT nanocomposite films. Whereas, Cano et al. (2015b) concluded that the overall migration rate of PVA/ST/CNC nanocomposite films was increased by $26.08 \%$ with increasing the CNC content from 0 to $5 \mathrm{wt} \%$ in $10 \%$ ethanol simulant. Nonetheless, the overall migration rate was decreased by $66.67 \%$ in the isooctane simulant with increasing the $\mathrm{CNC}$ content from 0 to $5 \mathrm{wt} \%$.

According to the Sustainable Packaging Coalition (2011) and Magnier and Crié (2015), the sustainable packaging should meet the following criteria: (i) useful, safe and healthy for individuals and communities throughout its life cycle, (ii) gathering market requirements for performance and cost, (iii) using renewable energy for manufacturing, transporting, and recycling, (iv) using renewable or recycled source materials, (v) using clean production technologies, (vi) made from materials healthy throughout their life cycle, (vii) designed to improve materials and energy, and (viii) effectively recovered and utilized in industrial/biological closed loop cycles. In this study, PVA, ST, and HNTs were selected as renewable materials for manufacturing nanocomposite films using solution casting as a clean production technology to meet the stringent criteria for sustainable packaging. Moreover, PVA/ST/GL/HNT nanocomposite films were characterized to investigate the effect of HNT contents on water resistance, transparency and biodegradability to study their material performance. The overall migration rates and HNT migration rates were explicitly investigated as well for PVA/ST/GL/HNT nanocomposite films with different food simulants mimicking hydrophilic, lipophilic, and acidic foodstuff conditions to evaluate their impact on critical food safety.

\section{EXPERIMENTAL WORK}

\section{Materials}

PVA (molecular weight: 89,000-98,000 g/mol and hydrolysis degree: $99 \%$ ), soluble ST from potatoes (100\% concentration), GL solution (molecular weight: $92.09 \mathrm{~g} / \mathrm{mol}$ and $60-100 \%$ concentration), and nitric acid with $70 \%$ concentration were purchased from Sigma-Aldrich Pty. Ltd, Australia. Furthermore, HNTs were donated by Imerys Tableware Asia Ltd, New Zealand in form of as-received ultrafine particles with a relative density of $2.53 \mathrm{~g} / \mathrm{cm}^{3}$. Glacial acetic acid with $96 \%$ concentration was supplied by Merck Pty. Ltd, Australia. Ethanol with $100 \%$ concentration was provided by Rowe Scientific Pty. Ltd, Australia. Aluminum standard solution with the concentration of $1,000 \mathrm{mg} / \mathrm{L}$ in nitric acid was provided by ThermoFisher Scientific Pty. Ltd, Australia. Silicon standard solution also with the same concentration in nitric acid was purchased from HighPurity Standards, Inc. All materials were used as received without further modifications.

\section{Fabrication of Films}

Solution casting method was employed to fabricate neat PVA, PVA blends (i.e., PVA/GL, PVA/ST, PVA/ST/GL), and PVA/ST/GL/HNT nanocomposite films. An aqueous solution of $5 \mathrm{wt} \% / \mathrm{v}$ PVA was obtained by dissolving $10 \mathrm{~g}$ PVA powders in $190 \mathrm{ml}$ deionised water at $35^{\circ} \mathrm{C}$ to prepare neat PVA films. The solution was gradually heated up to $85^{\circ} \mathrm{C}$ with continuous stirring via an IKA ${ }^{\circledR}$ - RCT basic magnetic stirrer at $500 \mathrm{rpm}$ for $3 \mathrm{~h}$. Equal amounts of clear PVA solutions were poured into petri dishes (dish diameter: $15 \mathrm{~cm}$ ) to produce thin films with uniform thickness of $0.110-0.125 \mathrm{~mm}$. Then these films were subsequently dried at $50^{\circ} \mathrm{C}$ for $24 \mathrm{~h}$. PVA/GL blends were also fabricated using the same procedure with the addition of $30 \mathrm{wt} \% \mathrm{GL}$ as a plasticizer during the last $30 \mathrm{~min}$ in the fabrication process. PVA/ST aqueous solution at the blend ratio of $80 / 20$ was prepared by mixing $8 \mathrm{~g}$ PVA and $2 \mathrm{~g}$ ST at room temperature in powder form, which was followed by dissolving them in $190 \mathrm{ml}$ deionised water according to the same procedure mentioned earlier. PVA/ST blends were also plasticized with $30 \mathrm{wt} \%$ GL to fabricate PVA/ST/GL blends as final biopolymer matrices for corresponding nanocomposites. HNTs at different nanofiller contents of $0.25,0.50,1,3$, and 5 wt\% were mechanically mixed using an IKA ${ }^{\circledR}$ - RW20 stirrer with $100 \mathrm{ml}$ deionised water at $50^{\circ} \mathrm{C}$ and $500 \mathrm{rpm}$ for $2 \mathrm{~h}$ to prepare the HNT aqueous suspension. Subsequently, the HNT suspension was sonicated using an ultrasonicating bath ELMA Ti-H-5 model at $50^{\circ} \mathrm{C}$ for $1 \mathrm{~h}$ with the frequency of $25 \mathrm{kHz}$ and power intensity of $90 \%$. The HNTs suspension was added in a dropwise manner to $100 \mathrm{ml} \mathrm{PVA} / \mathrm{ST} / \mathrm{GL}$ blend solution at $50^{\circ} \mathrm{C}$ and $500 \mathrm{rpm}$ with the aid of mechanical stirring for $30 \mathrm{~min}$. Finally, the prepared mixture solution was further homogenized via a magnetic stirrer at $50^{\circ} \mathrm{C}$ and $350 \mathrm{rpm}$ for $30 \mathrm{~min}$. The sonication process continued for extra $30 \mathrm{~min}$ in the same conditions to remove any entrapped air bubbles. Neat PVA, PVA blends, and PVA/ST/GL/HNT nanocomposite films were stored in a desiccator to dry all materials for at least 1 week prior to the following experimental characterization.

\section{CHARACTERIZATION METHODS Water Absorption Capacity $\left(W_{a}\right)$}

Water absorption capacity (or water uptake) tests were carried out according to ASTM standard D570-98 with the customized modification in term of sample size and water amount. Square samples of all materials in size of $2 \times 2 \mathrm{~cm}^{2}$ were pre-dried in a vacuum oven at $50^{\circ} \mathrm{C}$ for $24 \mathrm{~h}$, and then cooled to room temperature in a desiccator prior to weighing them as initial dry weight $\left(W_{o}\right)$. These samples were immersed in $100 \mathrm{ml}$ distilled water at room temperature until they reached an equilibrium condition after $24 \mathrm{~h}$. Further they were removed from water and their surfaces were gently dried with paper tissues. Afterwards, 
such samples were weighed again to measure their wet weight after the immersion $\left(W_{t}\right)$. Three samples for each batch have been tested along with reported average data and associated standard deviations. Water absorption capacity $\left(W_{a}\right)$ could be calculated according to the following equation:

$$
W_{a}(\%)=\frac{W_{t}-W_{o}}{W_{o}} \times 100 \%
$$

\section{Water Solubility $\left(W_{s}\right)$}

All swollen samples from water absorption tests were used to calculate the water solubility of materials according to ASTM standard D570-98. Samples were dried again in a vacuum oven at $60^{\circ} \mathrm{C}$ for $24 \mathrm{~h}$, then they were cooled down to room temperature in a desiccator for about $30 \mathrm{~min}$. The samples were weighed to acquire the dry weight after immersion $\left(W_{d}\right)$. The water solubility $\left(W_{s}\right)$ was then determined by using the formula below:

$$
W_{s}(\%)=\frac{W_{o}-W_{d}}{W_{o}} \times 100 \%
$$

\section{Water Contact Angle}

Water contact angles of neat PVA, PVA blends and PVA/ST/GL/HNT nanocomposite films were determined by using a Tensiometer KSV-CAM 101 (KSV Instruments Ltd., Finland). The surface hydrophilicity of films was evaluated by dropping $2 \mu \mathrm{L}$ deionised water on their flat surfaces using a Sessile Drop Half-Angle ${ }^{\mathrm{TM}}$ Tangent line method (SadeghHassani and Nafchi, 2014; Alipoormazandarani et al., 2015). At least five droplets at random places of different samples for each material batch were reported for test reliability.

\section{Uv-Vis Spectra}

The light transmittance of all materials was measured in a range of $200-800 \mathrm{~nm}$ on an ultraviolet-visible (UV-vis) spectrometer (Jasco-V670) with a blank glass plate being used as a reference. Light transmittance (T\%) of film samples, three samples per material batch, was determined with a scan rate of $200 \mathrm{~nm} / \mathrm{min}$.

\section{Migration Tests}

The migration rates of nanocomposite films were investigated according to (European Union Commission Regulation (EU) No. 10, 2011). In this study, three different food simulants, namely $10 \%(\mathrm{v} / \mathrm{v})$ ethanol solution (simulant A), 50\% (v/v) ethanol solution (simulant D1), and 3\% (w/v) acetic solution (simulant B) were employed to mimic hydrophilic, lipophilic and acidic foodstuff conditions, respectively. Approximately $1 \mathrm{dm}^{2}$ PVA/ST/GL blend films and their corresponding nanocomposite films with different HNT contents were immersed in individual glass bottles filled with $100 \mathrm{ml}$ food simulant solutions, as recommended by The European Standard EN. (2002). Glass bottles were tightened and then kept in the oven at $40^{\circ} \mathrm{C}$ for 10 days. Six samples were selected for each food simulant, in which initial three samples were used to calculate overall migration rates and the other three samples were particularly employed for migration rates of nanofillers. After 10 days, the bottles were removed from the oven, and then cooled down to room temperature before opening to reduce the evaporation of food simulants. All samples were removed from food simulants gently. The food simulants of initial three samples were evaporated, and the residues were dried overnight at $105^{\circ} \mathrm{C}$, which were then weighed after cooling down to room temperature with an analytical balance $( \pm 0.0001 \mathrm{~g}$ precision) to calculate the overall migration rates in $\mathrm{mg} / \mathrm{kg}$. Associated results were well compared with overall migration limit (OML) of $60 \mathrm{mg} / \mathrm{kg}$ (European Union Commission Regulation (EU) No 10/2011).

Inductivity coupled plasma-optical emission spectroscopy (ICP-OES) (PerkinElmer-Optima 8300) was implemented to evaluate the migration rates of $\mathrm{Al}^{+}$and $\mathrm{Si}^{+}$as a clear indication for the HNT migration from nanocomposite films. As a result, the residues for the other three samples were digested after being dried by using $15 \mathrm{ml} \mathrm{HNO}_{3}$ (solution concentration: 3\%) at $95^{\circ} \mathrm{C}$ for $2.5 \mathrm{~h}$. The digestion process was used to convert the residues of elements to an ionic state, and meanwhile to diminish the effect of matrices and reduce the contamination of equipment with dust. The operation parameters of ICPOES were listed in Table 1. For ICP-OES calibration, two blank solutions (i.e., distilled water and $3 \%$ nitric acid) and three standard solutions were used. Each standard solution contained an equal concentration of both $\mathrm{Al}^{+}$and $\mathrm{Si}^{+}$. They were prepared by a serial dilution of stock standard solutions with the same concentration of $1,000 \mathrm{mg} / \mathrm{L}$ for both $\mathrm{Al}^{+}$and $\mathrm{Si}^{+}$, which were further diluted to 1,5 , and $10 \mathrm{mg} / \mathrm{L}$ for $\mathrm{Al}^{+}$and $\mathrm{Si}^{+}$.

\section{Soil Burial Degradation}

The biodegradability of neat PVA, PVA blends, and PVA/ST/GL/HNT nanocomposites with different HNT contents was evaluated by a soil burial method according to the studies carried out by Thakore et al. (2001). Plastic containers with the $2 \mathrm{~L}$ capacity were filled with sieved agricultural soil obtained from local plant nursery. The square samples $\left(3 \times 3 \mathrm{~cm}^{2}\right)$ were weighed first to record their initial weight $\left(W_{o}\right)$, and then were buried at the under-surface depth of $5 \mathrm{~cm}$. Such degradation tests were conducted at room temperature with $40-50 \%$ relative humidity $(\mathrm{RH})$. In order to keep the identical conditions, the humidity level was controlled with a humidity meter and plastic containers were sprinkled with water to maintain the humidity at a constant level throughout the tests. The total testing period was monitored for 6 months (i.e., 24 weeks), in which these samples were removed from soil on a weekly basis in the initial 3 months, and then extended to every 3 weeks for the rest of months. Distilled water was utilized to wash samples and remove any soil from their surfaces. After these samples were dried in a vacuum

TABLE 1 | ICP-OES operating parameters for nanofiller migration tests.

\begin{tabular}{ll}
\hline Parameter & Value \\
\hline Plasma viewing mode & Radial and Axial \\
Plasma gas flow rate & $15 \mathrm{~L} / \mathrm{min}$ \\
Auxiliary gas flow rate & $0.50 \mathrm{~L} / \mathrm{min}$ \\
Nebuliser gas flow rate & $0.60 \mathrm{~L} / \mathrm{min}$ \\
Pump flow rate & $1.50 \mathrm{~mL} / \mathrm{min}$ \\
Radiofrequency & $1,400 \mathrm{Watts}$
\end{tabular}


oven at $70^{\circ} \mathrm{C}$ for $24 \mathrm{~h}$, they were weighed to record a dried weight $\left(W_{d}\right)$. As a result, biodegradation rate was calculated from the weight difference based on the given equation below:

$$
\text { Biodegredation rate }(\%)=\frac{W_{o}-W_{d}}{W_{o}} \times 100 \%
$$

Three samples for each batch were used for test reproducibility.

\section{Scanning Electron Microscopy (SEM)}

The surface morphology of neat PVA, PVA blends and PVA/ST/GL/HNT nanocomposite films were examined before, during, and after soil burial degradation tests by using a NEON40EsB field emission scanning electron microscope (FE-SEM) at an accelerating voltage of $2 \mathrm{kV}$. All samples were fixed on aluminum stubs and coated with platinum layer (layer thickness: $3 \mathrm{~nm}$ ) to improve the contrast of material constituents.

\section{RESULTS AND DISCUSSION}

\section{Water Absorption Capacity}

Since most biopolymers have the high sensitivity to water, the study of $W_{a}$ parameter is essential particularly in relation to food packaging applications (Sadegh-Hassani and Nafchi, 2014; Aloui et al., 2016). The addition of $30 \mathrm{wt} \%$ GL tended to moderately decrease the $W_{a}$ from $127.61 \%$ for PVA alone to $114.58 \%$ for PVA/GL blends, which could be associated with the strong interaction between PVA and GL resulting in the consumption of free hydroxyl groups of PVA in good agreement with Follain et al. (2005). On the other hand, as illustrated in Figure 1, one could see that PVA/ST blends had the highest $W_{a}$, which was ascribed to partial constituent miscibility with many free sites being occupied by water molecules. As expected, high hydrophilicity of starch with good water absorption inevitably yielded the increase in $W_{a}$ for PVA/ST blends (Ali, 2016), which was believed to be associated with typical hygroscopic nature of starch (Azahari et al., 2011; Ismail and Zaaba, 2011; Salleh et al., 2017). It was implied that the equilibrium with the environment could be reached by water gain and loss. Nonetheless, the GL plasticization effect in PVA/ST/GL blends gave rise to much lower $W_{a}$, which may benefit from its improvement of phase miscibility and constituent interactions, as evidenced by Zou et al. (2008) to conclude that the presence of GL improved the compatibility between PVA and ST and reduced the $W_{a}$.

The incorporation of HNTs in PVA/ST/GL/HNT nanocomposites further reduced the $W_{a}$ when compared with that of PVA/ST/GL blends, which could be explained by a typical reduction for water diffusion in the presence of HNTs within their morphological structures (Sadegh-Hassani and Nafchi, 2014). A drastic decrease in $W_{a}$ from 128.23 to $74.23 \%$ was attributed to the fact that embedded HNTs generated tortuous paths to hinder the water diffusion when the HNT content was increased from 0 to $1 \mathrm{wt} \%$. Similar effect of HNTs was reported on chitosan/HNT nanocomposites and chitosan/clove essential oil (CEO)/HNT nanocomposites by Lee et al. (2018). Their results showed that the $W_{a}$ of chitosan/HNT nanocomposites and chitosan/CEO/HNT nanocomposites was reduced by 42.17 and $43.31 \%$, respectively, at the HNT content

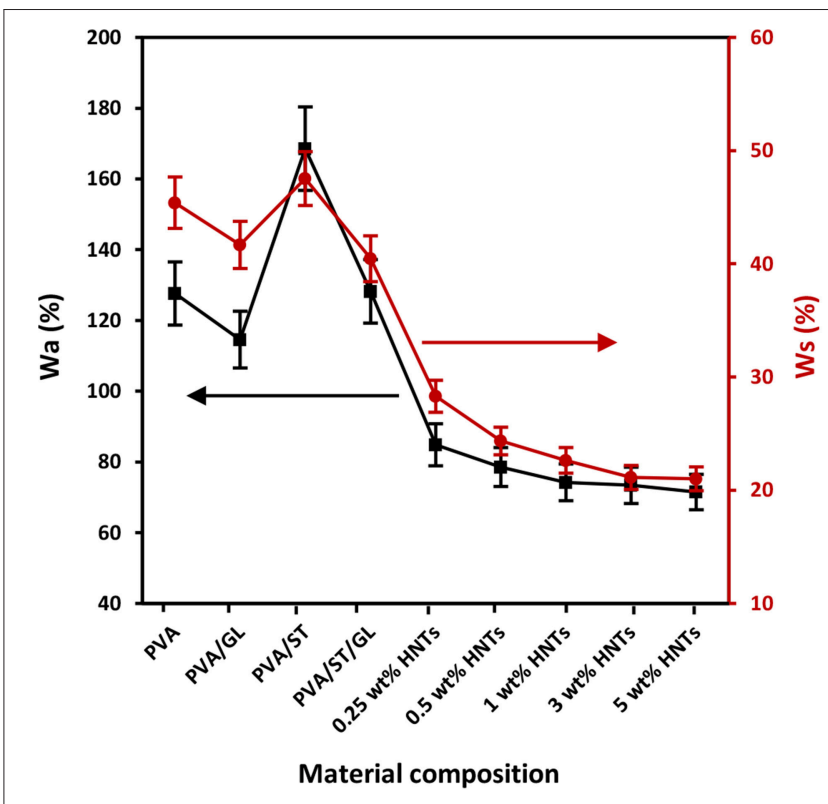

FIGURE 1 | Water absorption capacity $\left(\mathrm{W}_{\mathrm{a}}\right)$ and water solubility $\left(\mathrm{W}_{\mathrm{S}}\right)$ of neat PVA, PVA blends, and PVAST/GL/HNT nanocomposites at different HNT contents.

of $30 \mathrm{wt} \%$ as opposed to those of corresponding matrices due to the incorporation of nanofillers to affect the water absorption of matrices. Moreover, Abbasi (2012) stated that the $W_{a}$ of plasticized PVA/ST blend films significantly diminished by $50 \%$ with increasing the nano- $\mathrm{SiO}_{2}$ content from 1 to $5 \mathrm{wt} \%$ owing to highly active physical interaction between nanofillers and blend matrices to lower the number of hydroxyl groups in nanocomposite films. However, as illustrated in Figure 1, the $W_{a}$ appeared to show a minor reduction up to $3.69 \%$ beyond $1 \mathrm{wt} \%$ HNTs. This phenomenon arose from the HNT agglomeration mentioned in our previous work (Abdullah and Dong, 2017). The above-mentioned findings obtained in this study were also consistent with relevant results in plasticized PVA/ST/MMT nanocomposite films (Taghizdeh et al., 2012; Tian et al., 2017) as well as plasticized PVA/ST/nano- $\mathrm{SiO}_{2}$ nanocomposite films (Tang et al., 2008). Overall, the reduction of $W_{a}$ in nanocomposite films could be determined based upon nanofiller content and nanofiller dispersion within polymer matrices.

\section{Water Solubility}

The $W_{s}$ values of neat PVA, PVA blends and PVA/ST/GL/HNT nanocomposites were also demonstrated in Figure 1. In general, when material films have high $W_{a}$, they tend to easily dissolve in water as well because water molecules are absorbed onto hydroxyl groups particularly with hydrogen bonding to make the films easier to dissolve (Azahari et al., 2011). As such, $W_{a}$ and $W_{s}$ of all film materials possessed a very similar overall trend despite different magnitudes of parameters, as observed in Figure 1. The high values of $W_{s}$ were accepted because all the constituents had hydrophilic nature including PVA, ST, and GL, which was consistent with other studies (Cano et al., 2015a; 
Zanela et al., 2015). The $W_{s}$ of neat PVA was decreased by $8.21 \%$ when blended with GL to decrease the number of free hydroxyl groups interacting with water molecules. PVA/ST blends yielded the highest $W_{s}$ among all film materials resulting from the high water affinity of constituents according to the studies carried out by Negim et al. (2014). On the other hand, the $W_{s}$ of PVA/ST/GL blends was found to be reduced by $14.89 \%$ due to the presence of GL as a plasticizer to increase the miscibility between PVA and ST with better interfacial bonding (Zanela et al., 2015; Cano et al., 2015a).

The incorporation of HNTs to PVA/ST/GL blend films appeared to reduce the $W_{s}$ in a monotonically decreasing manner from 40.45 to $21.10 \%$ with increasing the HNT content from 0 to $5 \mathrm{wt} \%$ accordingly. This finding may be associated with the hydrophobic nature of HNTs resulting from a low number of hydroxyl groups on HNT surfaces (Liu et al., 2014). Moreover, $\mathrm{SiO}_{2}$ groups in HNTs had the ability to form strong hydrogen bonds by consuming free hydroxyl groups of polymer matrices and reduce the number of interaction sites with water molecules (Sadegh-Hassani and Nafchi, 2014). The $W_{s}$ reduction was more pronounced when the HNT content was in range of $0.25-1$ wt $\%$ as shown in Figure 1, because of good HNT dispersion within blend matrices in nanocomposite films. Whereas, such a decrease tendency became insignificant in range from 22.64 to $21.10 \%$ when increasing the HNT content from 1 to $5 \mathrm{wt} \%$ owing to the same HNT agglomeration issue mentioned in previous $W_{a}$ results. Our finding was in good accordance with those in plasticized PVA/ST/nano- $\mathrm{SiO}_{2}$ nanocomposites (Tang et al., 2008) and plasticized $\mathrm{PVA} / \mathrm{ST} / \mathrm{CaCO}_{3}$ nanocomposites (Kisku et al., 2014).

\section{Water Contact Angle}

Water contact angle of neat PVA, PVA blends, and PVA/ST/GL/HNT nanocomposites were measured in order to evaluate the hydrophilic nature of all material surfaces. It is well-known that low water contact angles $<90^{\circ}$ is referred to as the high material wettability whilst high contact angles $>90^{\circ}$ correspond to low wettability instead (Yuan and Lee, 2013). In other words, low water contact angles could signify higher hydrophilic nature of material surfaces and vice versa (Sadegh-Hassani and Nafchi, 2014, Alipoormazandarani et al., 2015). Apparently, neat PVA, which is considered as a popular water-soluble polymer, had a very low water contact angle of $28.35^{\circ}$ in good agreement with the previous result (Lim et al., 2015). The addition of GL to PVA only slightly increased the water contact angle for PVA/GL blend films by $0.33^{\circ} \mathrm{C}$, which could be interpreted by their insignificant reductions in $W_{a}$ and $W_{s}$. Moreover, with the incorporation of ST, the hydrophilic level of PVA/ST blend films was further improved, as evidenced by a decrease in water contact angle by $9.70^{\circ}$ compared with that of neat PVA counterpart, as illustrated in Figure 2. Moreover, an angle reduction of $2.78^{\circ} \mathrm{C}$ was reported for PVA/ST/GL blend films as opposed to that of neat PVA counterpart. The remarkable hydrophilic improvement for PVA blends, when compared with that of neat PVA, could be associated with more hydroxyl groups existing in PVA blends with the addition of ST.

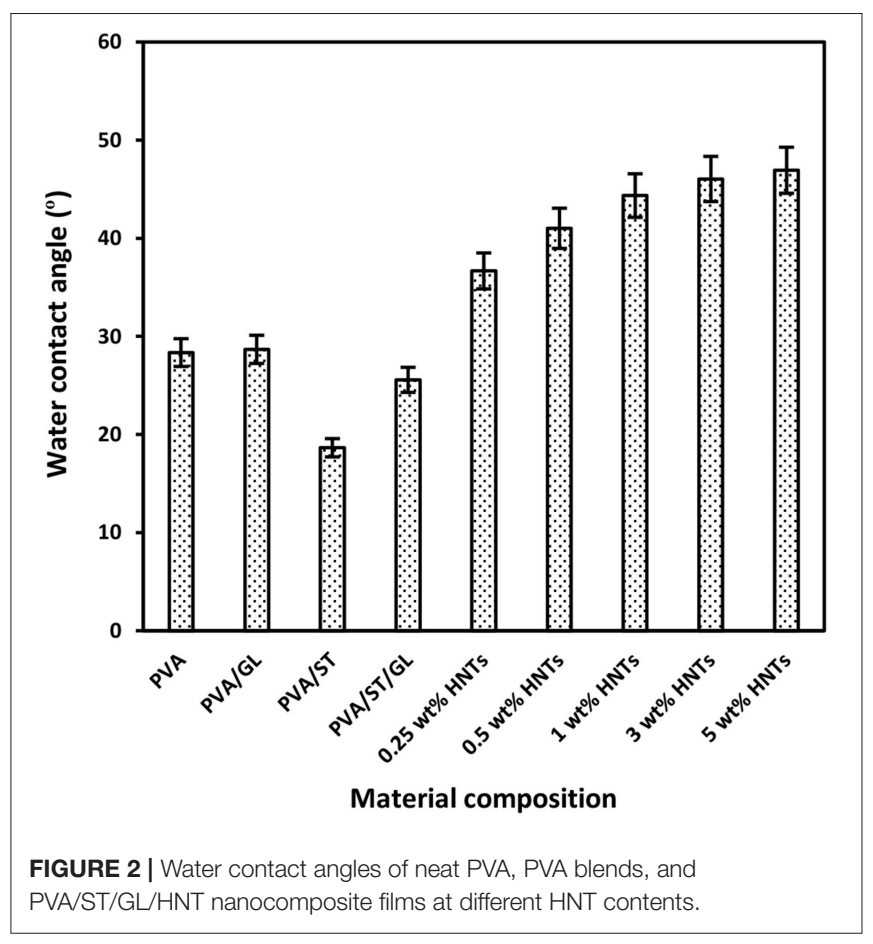

Such a finding further coincided with the increases in $W_{a}$ and $W_{s}$ of PVA blend films as compared to those of neat PVA.

On the other hand, a significant increase in water contact angles of nanocomposite films was pronounced from 25.57 to $46.93^{\circ} \mathrm{C}$ with increasing the HNT content from 0 to $5 \mathrm{wt} \%$. This was attributed to relatively hydrophobic nature of HNTs with a low number of hydroxyl groups leading to a decrease in water absorption capacity so that nanocomposite surfaces tended to be less hydrophilic (Liu et al., 2014, Sadegh-Hassani and Nafchi, 2014, Alipoormazandarani et al., 2015). Moreover, well-dispersed HNTs within blend matrices could use some free hydroxyl groups to build hydrogen bonding between them. It is well-known that the presence of nanofillers can lead to increasing the surface roughness of polymer matrices in nanocomposites (Grunlan et al., 2003). Therefore, the surface roughness of nanocomposite films was enhanced in the presence of HNTs resulting in the further increase in water contact angle based on Wenzel's theory (Wenzel, 1949). According to this theory, the surface hydrophobicity would be improved with increasing the surface roughness as follows (Kubiak et al., 2011):

$$
\cos \theta_{m}=r \cos \theta
$$

Where $\theta_{m}$ and $\theta$ are the measured and ideal contact angles, respectively, which can be calculated from perfect smooth surface like mirror, and $r$ is the roughness ratio where $r=1$ for smooth surfaces and $r>1$ for rough surfaces (Kubiak et al., 2011). Similarly, Biddecia et al. (2016) found the water contact angle of pectin/modified HNT nanocomposite film surfaces was increased by $6^{\circ} \mathrm{C}$ as compared with that of neat pectin matrices due to increasing the surface roughness of nanocomposite films with the addition of HNTs. 
PVA/ST/GL/HNT nanocomposite films were still within the hydrophilic-material range though their water contact angle was increased up to $21.57^{\circ} \mathrm{C}$ compared with that of PVA/ST/GL blends. The increased water contact angles for nanocomposite films were correlated well with corresponding reductions in their $W_{a}$ and $W_{s}$, with increasing the HNT contents.

\section{UV-Vis Spectra}

One of important features in food packaging for consideration is the film transparency in terms of light transmittance (T\%). Typical light transmittance curves for neat PVA, PVA blends and PVA/ST/GL/HNT nanocomposites as well as respective digital images of Curtin University logo observed through each of film batches were displayed in Figures 3A,B, respectively.

Neat PVA in possession of high crystallinity led to relatively high $T \%$ in range of $99-100.0 \%$, which was close to previously determined results elsewhere (Gupta et al., 2013). Depending on the phase miscibility, PVA/ST/GL had a slightly reduced T\% of 95.76-98.72\%, which was believed to be induced by the incident light loss from the light transmission, scattering, absorption, reflection and refraction when striking an interface while such a loss was increased especially at interfacial areas (Cai et al., 2016). Regardless of different wavelengths used, nanocomposite films yielded a significant decrease in T\% when the HNT content was increased from 0 to $5 \mathrm{wt} \%$, which was mostly pronounced at

A

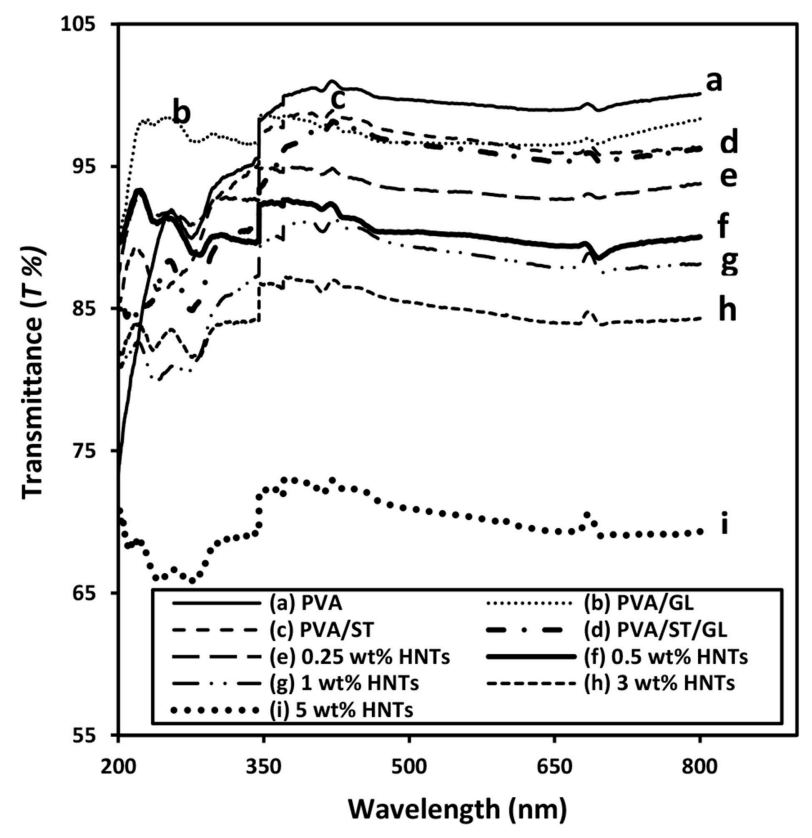

B
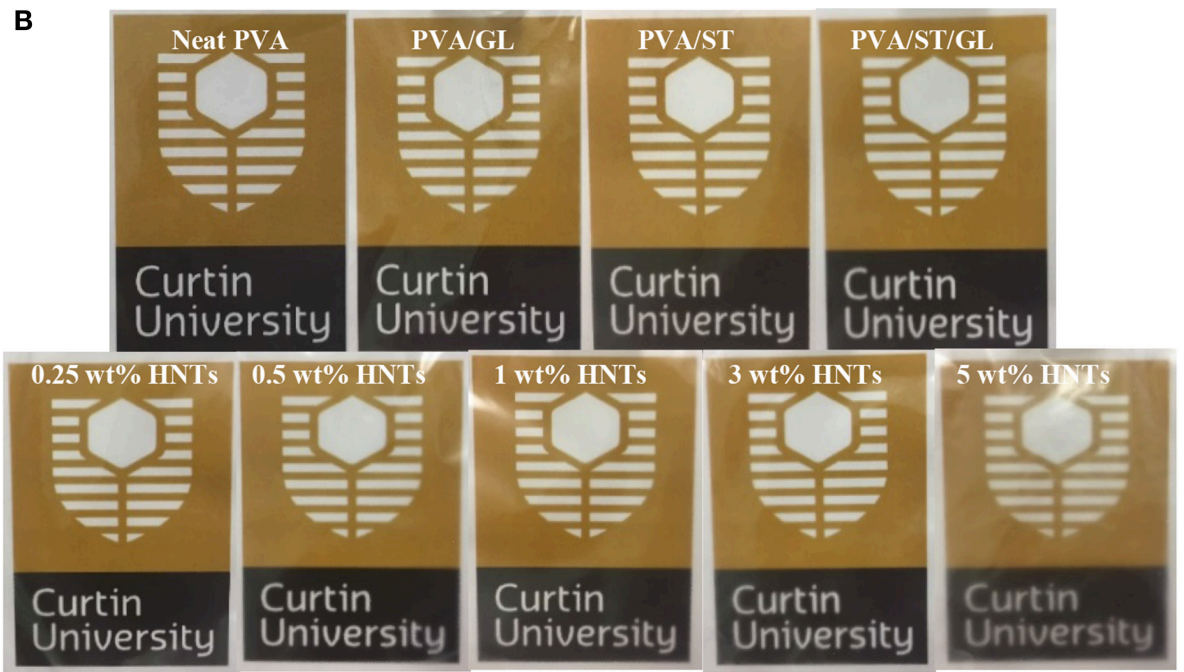

FIGURE 3 | (A) UV-vis spectra curves, and (B) digital images for the film transparency of neat PVA, PVA blends, and PVA/ST/GL/HNT nanocomposites at different HNT contents. 
the higher content level of $5 \mathrm{wt} \%$. Apparently, nanocomposite films with higher HNT contents inevitably led to higher surface roughness due to the inclusion of highly agglomerated nanofillers resulting in increased light scattering sites (Grunlan et al., 2003), as also confirmed by other studies in plasticized PVA/ST nanocomposite films (Tang et al., 2008, Akhavan et al., 2017). On the other hand, Lee et al. (2018) considered this reduction of $T \%$ as an advantage for food packaging applications since the UV-barrier properties of chitosan/CEO/HNT nanocomposite films could be improved leading to better protection of foodstuffs against nutrient loss, decolonization and lipid oxidation.

\section{Overall Migration Rate}

The overall migration rates in three different food simulants, namely $10 \%$ ethanol (simulant A), 50\% ethanol (simulant D1), and 3\% acetic acid (simulant B) were presented in Figure 4, which represented typical hydrophilic, lipophilic and acidic foodstuffs. It was evident that overall migration rates seemed to be much higher in PVA/ST/GL blends especially when contacting with simulant $\mathrm{A}$ as opposed to those of nanocomposite films, which stemmed from water soluble characteristic of PVA, ST and GL constituents in their blends (Mauricio-Iglesias et al., 2010). The overall migration rate of PVA/ST/GL blend and their nanocomposite films exceeded the OML of $60 \mathrm{mg} / \mathrm{kg}$ in food simulant A except those nanocomposites at HNT contents of 1 and $3 \mathrm{wt} \%$, which could be applicable to safe food packaging. The hydrophilic nature of PVA/ST/GL blends and their nanocomposite films could improve their solubility in any hydrophilic solution like food simulant A. It was easily understood that with the addition of HNTs as hydrophobic nanofillers, the solubility of PVA/ST/GL blend matrices could

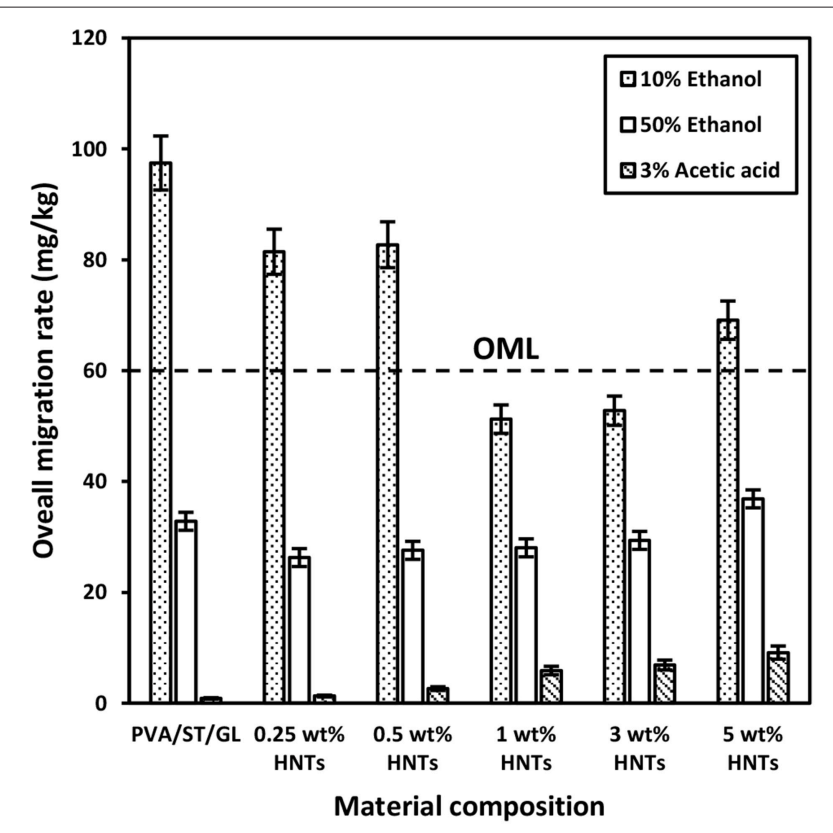

FIGURE 4 | Overall migration rates of PVASTT/GL blends and PVA/ST/GL/HNT nanocomposites in three different food simulants. diminish as earlier mentioned. On the other hand, strong interfacial bonding between HNTs and blend matrices was another plausible reason to reduce the mass transfer while in contact with food simulants. Therefore, it was clearly indicated that optimal HNT contents of 1 and $3 \mathrm{wt} \%$ had significant impact on the remarkable reductions of overall migration rates by 47.41 and $45.85 \%$ in food simulant $\mathrm{A}$, respectively, as opposed to that of PVA/ST/GL blends. Notwithstanding that the overall migration rate of nanocomposite films with the inclusion of 5 wt\% HNTs was increased again by $30.97 \%$ possibly due to the HNT agglomeration, it was still lower than those of PVA/ST/GL blends and nanocomposites at the HNT contents of 0.25 and $0.50 \mathrm{wt} \%$. Such a finding was further proven by Cano et al. (2015b), when dealing with PVA/ST/CNC nanocomposite films. With respect to simulant D1, overall migration rates of both PVA/ST/GL blends and nanocomposites were unanimously well below the OML of $60 \mathrm{mg} / \mathrm{kg}$. The overall migration rates of nanocomposites were decreased at HNT contents of $0.25-3$ $\mathrm{wt} \%$ relative to that of PVA/ST/GL matrices and the maximum reduction by $19.93 \%$ was recorded at the lowest HNT content of $0.25 \mathrm{wt} \%$. Finally, the lowest overall migration rates were recorded in food simulant $\mathrm{B}$ to mimic acidic foodstuffs at the $\mathrm{pH}$ level below 4.50. There was a clear modestly increasing trend for overall migration rates of nanocomposites from 1.29 to 9.13 $\mathrm{mg} / \mathrm{kg}$ when increasing the HNT content from 0 to $5 \mathrm{wt} \%$. The overall migration rates of PVA/ST/GL/HNT nanocomposites were highly influenced by the selection of food simulants in which they possessed a higher sensitivity to hydrophilic foodstuffs, followed by lipophilic foodstuffs and then acidic foodstuffs with the least impact. In view of safe food packaging, all polymer blend and nanocomposite films were satisfied with the OML criterion to be used for lipophilic and acidic foodstuff packaging while only nanocomposite films at the HNT contents of $1-3 \mathrm{wt} \%$ were suitable for hydrophilic foodstuffs.

\section{Migration of HNTs}

The HNT migration was evaluated by detecting the presence of $\mathrm{Al}^{+}$and $\mathrm{Si}^{+}$in migrated materials. There were no traces of $\mathrm{Al}^{+}$and $\mathrm{Si}^{+}$detected in migrated materials from PVA/ST/GL blend films. In other words, the overall migration rate of such polymer blend films clearly reflected the quantities of migrated polymeric molecules to different food simulants. On the other hand, different quantities of $\mathrm{Al}^{+}$and $\mathrm{Si}^{+}$were found in all migrated materials based on nanocomposite films, as shown in Figures 5A,B, respectively. The migration rates of both $\mathrm{Al}^{+}$ and $\mathrm{Si}^{+}$were in good agreement with the overall migration rates in different food simulants. That means higher quantities of $\mathrm{Al}^{+}$and $\mathrm{Si}^{+}$were detected in food simulant $\mathrm{A}$, which was followed by food simulant D1 along with their lowest quantities in food simulant B. Such a finding could be due to the hydrophilic nature of food simulant A, which worked as solvent-like water on nanocomposite films resulting in increasing the chain mobility of polymeric molecules and improving the release of nanofillers from nanocomposite films. Lee et al. (2018) discussed similar results based on the migration of CEO in chitosan/CEO films and chitosan/CEO/HNT nanocomposite films by migrating simulant molecules from external surfaces 

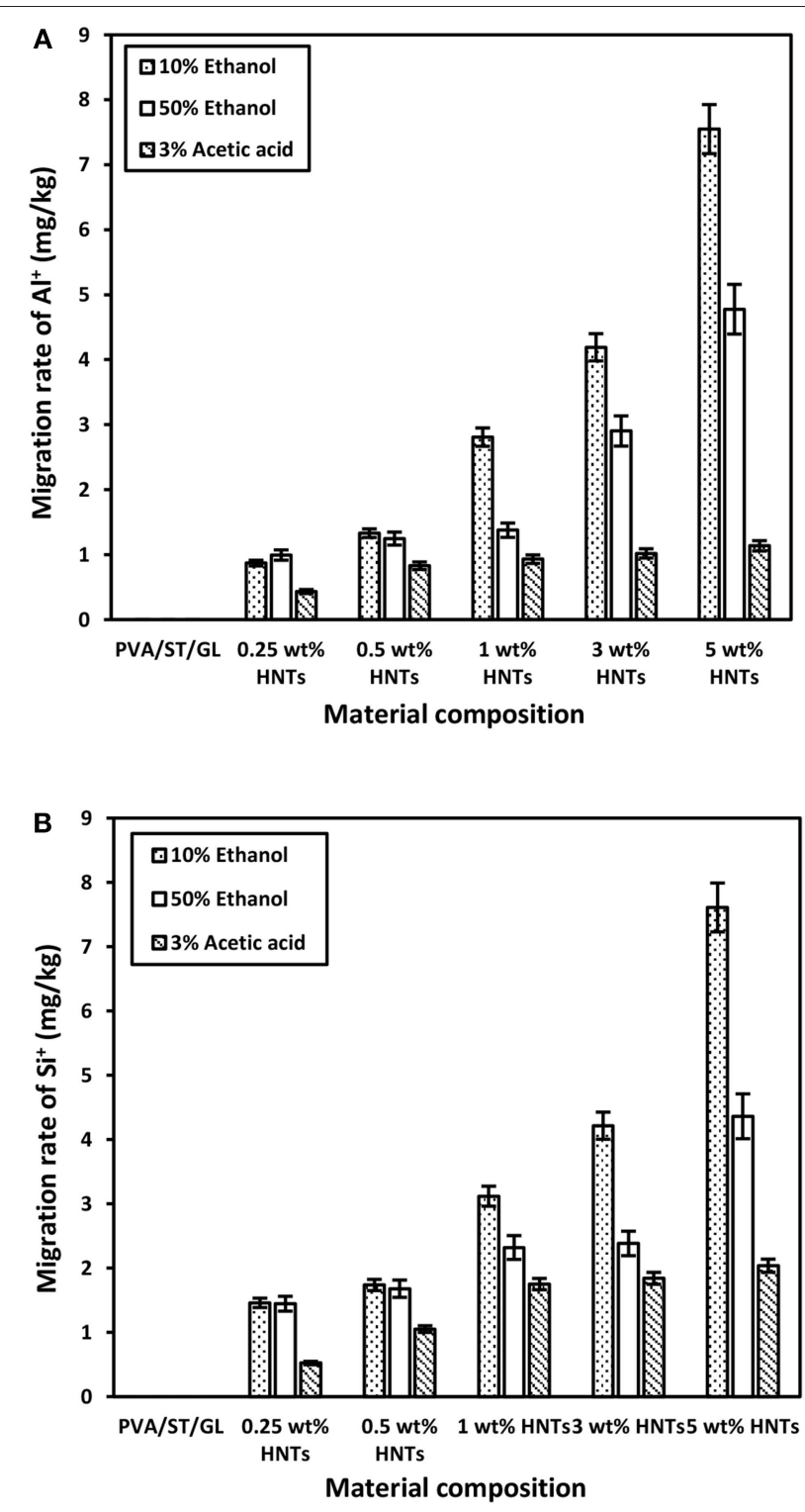

FIGURE 5 | Migration rates of (A) $\mathrm{Al}^{+}$and (B) $\mathrm{Si}^{+}$obtained from PVA/ST/GL blends and PVASTT/GL/HNT nanocomposites in three different food simulants.

of the films to internal film structures, which resulted in weak and lost bonding networks between film constituents. As such, active agents trapped by continuous polymer matrices could be easily released, particularly when polymeric molecules were soluble in simulants. The amounts of migrated $\mathrm{Al}^{+}$ and $\mathrm{Si}^{+}$in food simulant $\mathrm{A}$ were increased by 766.67 and $424.82 \%$ with increasing the HNT content from 0.25 to 5 wt\%, respectively, which was followed by 381.82 and $202.87 \%$ in simulant D1 as well as 162.79 and $290.38 \%$ in simulant B accordingly. Once again, food simulant B had the weakest interaction with nanocomposite films especially for migrated $\mathrm{Al}^{+}$ related to the inert nature of $\mathrm{Al}$ element to acidic foodstuffs, and this finding was consistent with the overall migration rate results mentioned earlier. Such phenomenal results may be interpreted by two different mechanisms of diffusion for the penetration of food simulants in nanocomposite films, and embedding to represent intermolecular forces between penetrated molecules and film materials according to the dual sorption theory (Huang et al., 2011; Farhoodi et al., 2014). Since the diffusion process could be much faster than embedding counterpart, the diffusion of hydrophilic molecules in PVA/ST/GL/HNT nanocomposite films further enlarged interconnecting spaces between polymeric chains to better facilitate the HNT release from nanocomposite films. As such, fast diffusion in film materials played a leading role in controlling migration rates, which tended to be much higher in hydrophilic foodstuffs as opposed to those in lipophilic and acidic counterparts.

According to European Union Commission Regulation (EU) No. 10 (2011), there was no specific migration limits for $\mathrm{Al}^{+}$ and $\mathrm{Si}^{+}$that could be followed for comparison. However, HNTs were classified as a natural, biocompatible, non-toxic and EPA 4A listed material (Kamble et al., 2012; Kryuchkova et al., 2016; Lvov et al., 2016). Consequently, HNTs were widely used for medical applications such as drug delivery particularly for non-injectable drug formula, bone cement, dentist resin, tissue scaffolds, cosmetics, and antiseptic treatment of hospitals (Kamble et al., 2012; Lvov et al., 2016; Fizir et al., 2018). Numerous studies were carried out on the toxicity of HNTs by the in-vitro and in-vivo experiments. Their results showed that HNTs did not possess the toxicity up to a concentration of $75 \mu \mathrm{g} / \mathrm{mL}$ and about $90 \%$ of tested cells were still viable (Vergaro et al., 2010; Fizir et al., 2018; Santos et al., 2018). Whereas, other studies further extended such a concentration to $100 \mu \mathrm{g} / \mathrm{mL}$ (Lvov et al., 2016), and $200 \mu \mathrm{g} / \mathrm{mL}$ (Guo et al., 2012). As such, the migrated amounts of HNTs from PVA/ST/GL/HNT nanocomposite films were well within the safe limits (based on the part per million (ppm) as a scale for comparison) without any toxic effect on the nanoparticle intake by human bodies. Overall, no great difference was shown between the quantities of $\mathrm{Al}^{+}$and $\mathrm{Si}^{+}$migrated in each food simulant as a result of similar element contents of $\mathrm{Al}(20.90 \%)$ and $\mathrm{Si}(21.76 \%)$ detected in the HNT composition (Abdullah et al., 2017). It was expected that increasing the HNT content from 0.25 to $5 \mathrm{wt} \%$ inevitably enhanced the quantities of $\mathrm{Al}^{+}$and $\mathrm{Si}^{+}$despite various increasing levels depending on the use of three different food simulants. The consistently highest quantities of migrated $\mathrm{Al}^{+}$and $\mathrm{Si}^{+}$with the inclusion of 5 wt $\%$ HNTs in nanocomposite films might also be described by the detrimental effect of nanofiller agglomeration at high HNT content levels to induce their poor interfacial bonding with blend matrices (Abdullah and Dong, 2017) when compared with well-dispersed HNTs at the low contents, as shown in Figure 6. Consequently, the release of highly agglomerated HNTs to food simulants appeared to be much easier than those well-dispersed HNTs embedded in matrices in nanocomposite films.

\section{Soil Burial Degradation}

The biodegradability of most biopolymers was highly related to the $W_{a}$ and $W_{s}$ since their degradation was initiated with the water absorption on their surfaces, and then followed 


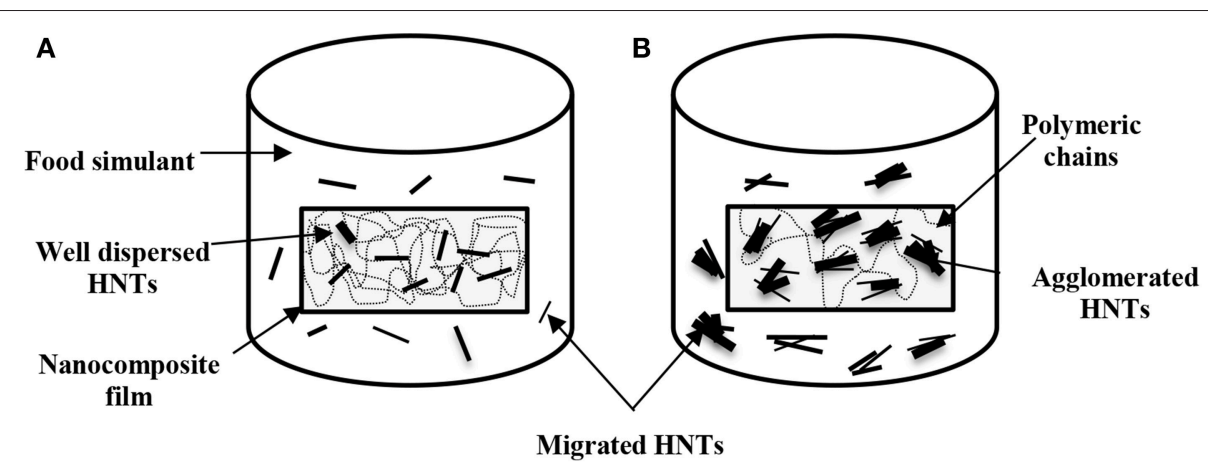

FIGURE 6 | Schematic diagram of released HNTS from PVAST/GL/HNT nanocomposite films in a typical food simulant based on (A) well-dispersed HNTs at low nanofiller contents and (B) agglomerated HNTs at high nanofiller contents.

by the growth of microorganism like bacteria and fungi. On the other hand, high material solubility also accelerated the biodegradability, which was particularly the case in soil (Guohua et al., 2006; Zanela et al., 2015). The digital images of films before and after 24-week biodegradation tests clearly indicated that PVA/ST, PVA/ST/GL blends and PVA/ST/GL/HNT nanocomposite films diminished in size and intended to become more fragile and wrinkling films, as depicted in Figure 7A. Neat PVA and PVA/GL blend films possessed relatively good transparency after biodegradation tests. Whereas, PVA/ST, PVA/ST/GL blends and PVA/ST/GL/HNT nanocomposite films tended to undergo a great color change and become more yellowish after biodegradation tests. This phenomenon could be associated with the presence of potato-based soluble ST prone to the strong attack by microorganism when compared with the former PVA and PVA/GL blends (Hejri et al., 2013).

Biodegradation rates of neat PVA, PVA blends and PVA/ST/GL/HNT nanocomposites were evaluated as a function of time over 24-week periods, as shown in Figure 7B, which could be clearly divided into an "active-state period" in the initial 3 weeks where most materials degraded in very rapid pace as well as "steady-state period" for the rest of time at a relatively slow rate until the end of tests, as confirmed by other studies (Guohua et al., 2006; Hejri et al., 2013; Singha and Kapoor, 2014). Azahari et al. (2011) stated that such a phenomenon could take place in soil and compost degradation due to the composting process including active composting and curing stages. In the active stage, a strong microbial activity happened due to rising temperatures resulting from oxygen availability. In comparison, as the temperature decreased in the curing stage, the degradation process continued with a relatively slow rate. Neat PVA films possessed the lowest biodegradation rate of 5.87\% among all materials after 24 weeks in this study, which suggested that PVA had high resistance to biodegradation in soil, and this slight weight loss was associated with its typical characteristic of hydrolysability (Imam et al., 2005; Guohua et al., 2006; Kopcilova et al., 2013). Normally, carbon backbone polymers like PVA are not susceptive to biodegradation (Kale et al., 2007). However, polymeric chains of PVA were cleaved, decreased in molecular weight and finally consumed by microorganisms due to the enzymatic oxidation of hydroxyl and carbonyl groups, which was then followed by the hydrolysis of these groups (Kale et al., 2007). Nonetheless, blending GL with PVA in film materials was found to increase their biodegradation rate up to $23.33 \%$ because it increased the chain mobility of PVA molecules with the further improvement of water diffusion through their morphological structures. Moreover, the addition of ST, when considered as a fully biodegradable polymer (Guohua et al., 2006; Azahari et al., 2011), inevitably further increased the biodegradation rate up to $39.54 \%$, which was attributed to easier microorganism attack to ST material structures than those of neat PVA (Hejri et al., 2013, Kale et al., 2007). It was well reported that increasing the ST content could improve the biodegradation rate of PVA/ST blends in a linear manner (Jayasekara et al., 2003; Azahari et al., 2011; Tanase et al., 2015). With respect to the biodegradability of nanocomposite films, it was manifested that their biodegradation rate dropped linearly from 56.94 to $41.28 \%$ with increasing the HNT content from 0 to $1 \mathrm{wt} \%$, which directly benefited from the formation of hydrogen bonds between well-dispersed HNTs and blend matrices so that water diffusion, mass transfer and infiltration speed of microorganisms were restricted (Tang et al., 2008). At the HNT contents of 3 and $5 \mathrm{wt} \%$, the biodegradation rates were modestly increased to 45 and $45.80 \%$, respectively, due to the agglomeration of HNTs, which were still more significant when compared with that of neat PVA, in good agreement with other results (Imam et al., 2005; Tang et al., 2008; Heidarian et al., 2017).

\section{SEM Analysis}

Neat PVA, PVA blends and PVA/ST/GL/HNT nanocomposites were also examined via SEM analysis to understand structural damage due to soil burial degradation over different time periods, namely at initial week $(0 \mathrm{~W})$, during the active-state periods after 1 week $(1 \mathrm{~W})$ and 3 weeks $(3 \mathrm{~W})$ as well as at the end of the degradation tests (i.e., after $24 \mathrm{~W}$ ), as shown in Figures 8, 9. Only morphological structures of nanocomposite 

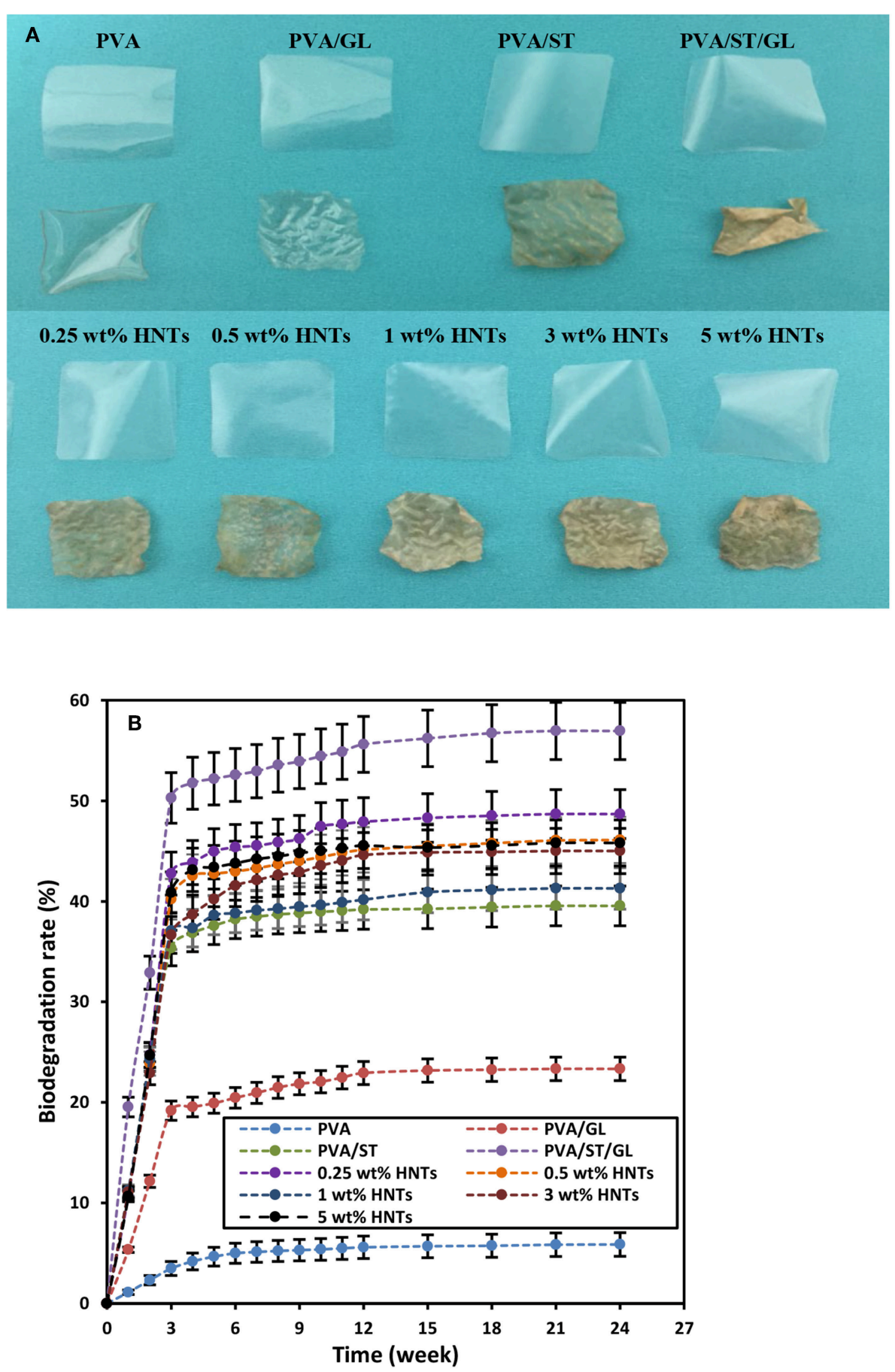

FIGURE 7 | (A) Digital images before and after biodegradation tests, and (B) biodegradation rates of neat PVA, PVA blend and PVA/ST/GL/HNT nanocomposite films.

films reinforced with 0.25 and 5 wt $\%$ were demonstrated as two typical cases for low and high HNT contents. As seen in Figure 8, neat PVA and PVA/GL blend films revealed similar smooth surface morphology as reported elsewhere (Cano et al., 2015b,c), which was completely different from a multitude of globular structures with much higher surface roughness for PVA/ST blends. The latter observation was related to the incompatibility between PVA and ST as two separate constituents in blend films with the absence of plasticizers such as GL, which was in good agreement with Cano et al. (2015c). Such partial phase miscibility effect in PVA/ST blends in this study was believed to cause their higher $W_{a}$ and $W_{s}$. It was 


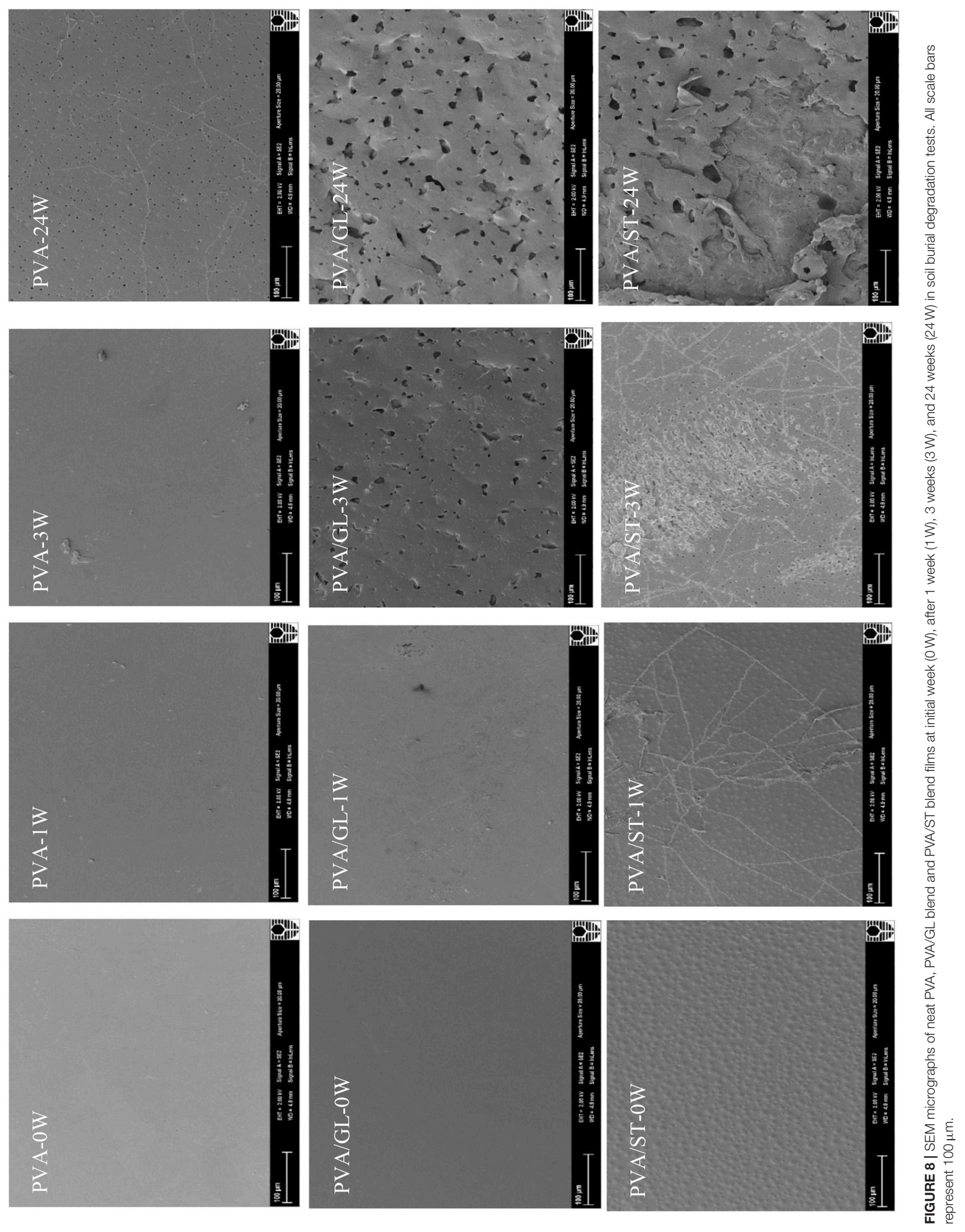




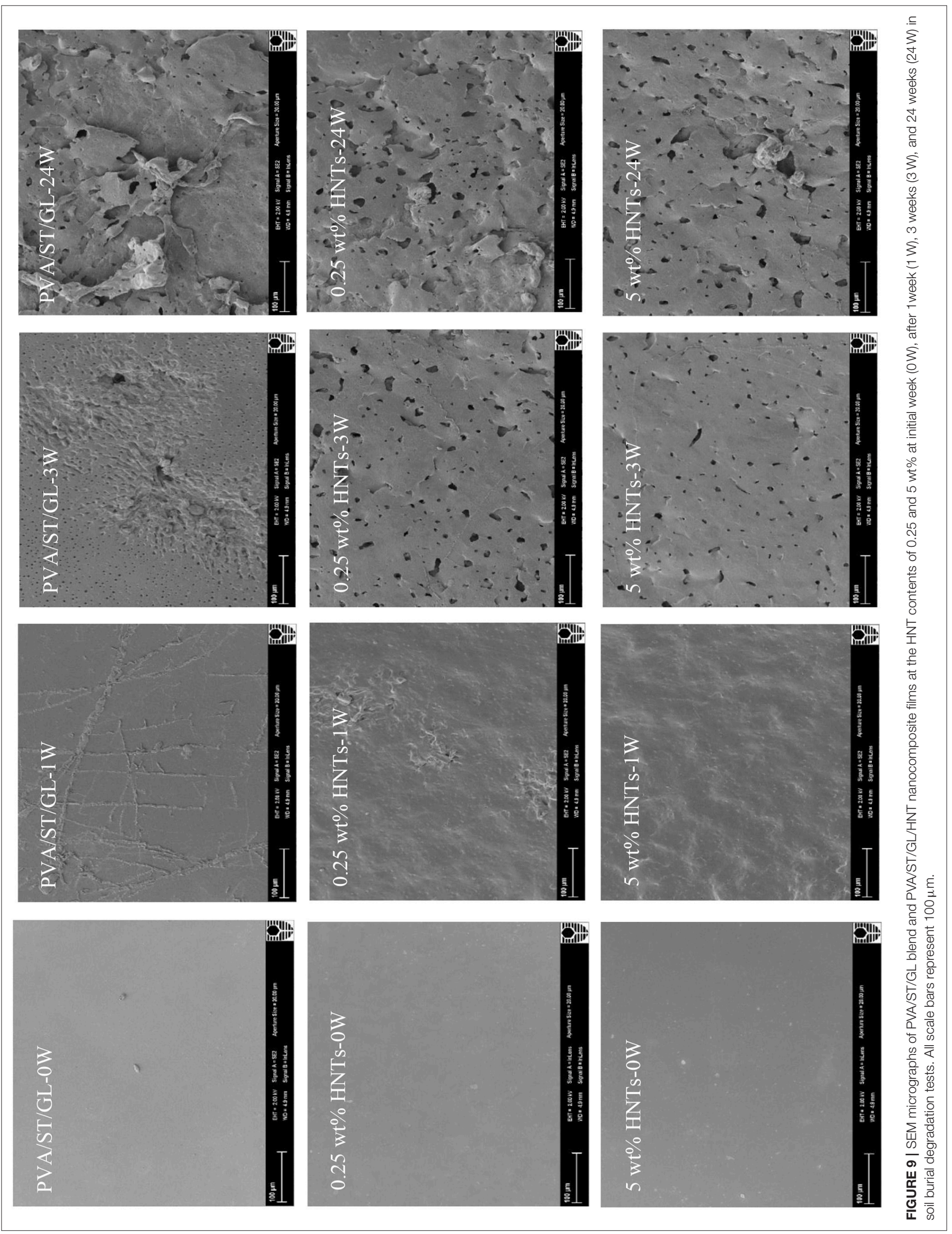


also interesting to note that smooth surface morphology took place in PVA/ST/GL blend films instead mainly because better compatibility between PVA and ST could be obtained in the presence of GL with their resulting slight reductions of $W_{a}$ and $W_{s}$ when compared with those of PVA/ST blend films. The addition of HNTs also increased the surface roughness of nanocomposite films particularly with the inclusion of $5 \mathrm{wt} \%$ HNTs in comparison with that of PVA/ST/GL blend films, as depicted in Figure 9.

In particular, neat PVA films did not show clear surface changes during the testing periods, as confirmed with the film appearance in Figure 8. "Branched traces" could be found slightly on the surfaces of PVA/GL blend films, but more clearly observed on the surfaces of PVA/ST blend films and PVA/ST/GL blend films, which are known as "fungal hyphae." According to Qiu and Netravali (2015) these fungal hyphae could be commonly generated during the biodegradation process at a suitable temperature level. The number and extension of these fungal hyphae increased with time by crossing each other to form grooves, as indicated elsewhere (Sang et al., 2002). The presence of fungal hyphae could be associated with high degradation rates during the first weeks of activestate periods. Nanocomposite films had rough surfaces after 1 week, but the HNTs prevented the formation of these fungal hyphae because the presence of nanofillers reduced the infiltration speed of microorganisms in good accordance with Tang et al. (2008).

Neat PVA films possessed much rougher surfaces after 3 weeks while PVA/GL blend films demonstrated considerable changes such as the formation of pores with average pore diameters in range of $0.12-1.64 \mu \mathrm{m}$. The presence of GL assisted in the chain-mobility improvement of polymeric molecules (Talja et al., 2007; Ismail and Zaaba, 2011), further increased the infiltration speed of microorganisms within blend films, and in turn enhanced the biodegradation rate when compared with that of neat PVA counterparts. The degradation process induced by fungal hyphae was much faster in PVA/ST blend films and PVA/ST/GL blend films than that in neat PVA films along with the existence of many small open pores in some surface areas (Negim et al., 2014). Nanocomposite films revealed a relatively small number of pores as compared with PVA/ST/GL blend films despite their bigger average pore diameters in range of $0.21-3.05 \mu \mathrm{m}$. After 24 weeks, fine porous structures were manifested for the surface morphology of neat PVA films with average pore diameters in range of $0.06-$ $0.72 \mu \mathrm{m}$, which were more or less uniformly distributed around PVA film surfaces with low degradation rates. Nonetheless, surface morphological structures of PVA/ST and PVA/ST/GL blends as well as PVA/ST/GL/HNT nanocomposites were observed to deteriorate progressively from film external surfaces to their internal layers. Finally, the presence of ST had remarkable effect on morphological structures of PVA/ST, PVA/ST/GL, and nanocomposite films as opposed to those of neat PVA films.

\section{CONCLUSIONS}

Biopolymers were widely used to reduce plastic wastes for environmental sustainability. PVA has been considered as one of attractive synthetic biopolymers over a few decades. PVA was blended with ST and GL to improve its biodegradability and compatibility whilst reduce material cost. PVA/ST/GL blend films had poor water resistance because all the components belonged to hydrophilic materials.

The incorporation of HNTs improved the water resistance of PVA/ST/GL/HNT nanocomposite films by reducing the $W_{a}$ and $W_{s}$ by 44.24 and $48.05 \%$, respectively, with increasing HNT contents from 0 to $5 \mathrm{wt} \%$. The relatively hydrophobic nature of HNTs in addition to the generation of hydrogen bonds between polymeric matrices and nanofillers could restrict the diffusion of water molecules through polymer matrices. These findings were evidenced by decreasing the hydrophilic nature of nanocomposite films with the incorporation of HNTs, which was reflected by increasing the water contact angle of nanocomposite films by $21.36^{\circ} \mathrm{C}$ when compared with that of PVA/ST/GL blend films. Small HNT contents between 0.25 and $1 \mathrm{wt} \%$ had higher influence on the improvement of water resistance due to good HNT dispersion compared with typical HNT agglomeration at high nanofiller content levels beyond $1 \mathrm{wt} \%$, thus resulting in the reduction of tortuous effect for water diffusivity. The use of PVA/ST/GL/HNT nanocomposite films still demonstrated the good transparency at an acceptable level despite its reduction from 96.23 to $70.48 \%$ when the HNT content was increased from 0 to $5 \mathrm{wt} \%$ at the wavelength of $550 \mathrm{~nm}$. The similar trend was also observed with respect to the biodegradation rate of such nanocomposite films decreasing from 56.94 to $41.28 \%$ with increasing the HNT contents from 0 to 1 wt $\%$ where HNTs were well-dispersed. This result is in contrast with a further increase up to $45.80 \%$ with the inclusion of $5 \mathrm{wt} \%$ highly agglomerated HNTs despite being still higher than that of PVA/ST blend films. HNTs had significant effect on decreasing the overall migration rates of nanocomposite films in $10 \%$ ethanol food simulant as opposed to PVA/ST/GL blend films. Furthermore, the overall migration rates of nanocomposite films in 50\% ethanol and 3\% acidic food simulants were lower than the OML to meet stringent food safety requirements along with very low risk of nanoparticle migration of HNTs. Consequently, PVA/ST/GL/HNT nanocomposite films could be potentially used as versatile thin-film materials with high water resistance, good biodegradability, acceptable transparency and overall migration rates to target sustainable food packaging particularly for lipophilic and acidic foodstuffs.

\section{AUTHOR CONTRIBUTIONS}

ZA did the experimental work and preparation, characterization, and property measurements of material samples. ZA and YD analyzed the data and jointly prepared the research manuscript. 


\section{ACKNOWLEDGMENTS}

ZA would like to acknowledge the Higher Committee for Developing Education (HCDE) in Iraq to support a $\mathrm{Ph}$. D scholarship at Curtin University. This study was undertaken using the SEM equipment (ARC LE0775553)

\section{REFERENCES}

Abbasi, Z. (2012). Water resistance, weight loss and enzymatic degradation of blends starch/polyvinyl alcohol containing $\mathrm{SiO}_{2}$ nanoparticle. J. Taiwan. Inst. Chem. Eng. 43, 264-268. doi: 10.1016/j.jtice.2011.10.007

Abdullah, Z. W., and Dong, Y. (2017). Preparation and characterisation of poly(vinyl) alcohol (PVA)/starch (ST)/halloysite nanotube (HNT) nanocomposite films as renewable materials. J. Mater. Sci. 53, 3455-3469. doi: 10.1007/s10853-017-1812-0

Abdullah, Z. W., Dong, Y., Davies, I. J., and Barbhuiya. S. (2017). PVA, PVA blends, and their nanocomposites for biodegradable packaging application. Polym. Plast. Technol. Eng. 56:1307-1344. doi: 10.1080/03602559.2016.1275684

Akhavan, A., Khoylou, F., and Ataeivarjovi, E. (2017). Preparation and characterization of gamma irradiated Starch/PVA/ZnO nanocomposite films. Radiat. Phys. Chem. 138, 49-53. doi: 10.1016/j.radphyschem.2017.02.057

Ali, M. (2016). Synthesis and study the effect of HNTs on PVA/chitosan composite material. Int. J. Chem. Molecul. Nucl. Mater. Metall. Eng. 10, 234-240. doi: 10.5281/zenodo.1111917

Alipoormazandarani, N., Ghazihoseini, S., and Nafchi, A. M. (2015). Preparation and characterization of novel bionanocomposite based onsoluble soybean polysaccharide and halloysite nanoclay. Carbohyd. Polym. 134, 745-751. doi: 10.1016/j.carbpol.2015.08.059

Aloui, H., Khwaldia, K., Hamdi, M., Fortunati, E., Kenny, J. M., Buonocore, G. G., et al. (2016). Synergistic effect of halloysite and cellulose nanocrystals on the functional properties of PVA based nanocomposites. ACS Sust. Chem. Eng. 4, 794-800. doi: 10.1021/acssuschemeng.5b00806

Aslam, M., Kalyar, M. A., and Raza, Z. A. (2018). Polyvinyl alcohol: a review of research status and use of polyvinyl alcohol based nanocomposites. Polym. Engin. Sci. 58, 2119-2132. doi: 10.1002/pen.24855

Avella, M., De, V. , Jan, J., Errico, M. E., Fischer, S., Vacca, P., and Volpe, M. G. (2005). Biodegradable starch/clay nanocomposite films for food packaging applications. Food. Chem. 93, 467-474. doi: 10.1016/j.foodchem.2004.10.024

Azahari, N. A., Othman, N. N., and Ismail, H. (2011). Biodegradation studies of polyvinyl alcohol/corn starch blend films in solid and solution media. J. Phys. Sci. 22, 15-31.

Biddecia, G., Cavallaro, G., Di Blasi, F., Lazzara, G., Massaro, M., Milioto, S., et al. (2016). Halloysite nanotubes loaded with peppermint essential oil as filler forfunctional biopolymer film. Carbohyd. Polym. 152, 548-557. doi: 10.1016/j.carbpol.2016.07.041

Bott, J., Störmer, A., and Franz, R. (2014a). A model study into the migration potential of nanoparticles from plastics nanocomposites for food contact. Food. Packag. Shelf. Life. 2, 73-80. doi: 10.1016/j.fpsl.2014.08.001

Bott, J., Störmer, A., and Franz, R. (2014b). Migration of nanoparticles from plastic packaging materials containing carbon black into foodstuffs. Food Addit. Contam. Part A Chem. Anal. Control Expo. Risk Assess. 31, 1769-1782. doi: 10.1080/19440049.2014.952786

Busolo, M. A., Fernandez, P., Ocio, M. J., and Lagaron, J. M. (2010). Novel silver-based nanoclay as an antimicrobial in polylactic acid food packaging coatings. Food Addit. Contam. Part A Chem. Anal. Control Expo. Risk Assess. 27, 1617-1626. doi: 10.1080/19440049.2010.506601

Cai, J., Chen, J., Zhang, Q., Lei, M., He, J., Xiao, A., et al. (2016). Wellaligned cellulose nanofiber-reinforced polyvinyl alcoholcomposite film: mechanical and optical properties. Carbohyd. Polym. 140, 238-245. doi: 10.1016/j.carbpol.2015.12.039

Cano, A., Fortunati, E., Chafer, M., Gonzalez-Martinez, C., Chiralt, A., and Kenny., J. M. (2015b). Effect of cellulose nanocrystals on the properties of pea starch-poly(vinyl alcohol) blend films. J. Mater. Sci. 50, 6979-6992. doi: 10.1007/s10853-015-9249-9 with the technical assistance from Ms. Elaine Millers at Microscopy and Microanalysis Facility, the John deLaeter Centre, Curtin University. Additionally, migration tests were conducted with the aid of Mr. Andrew Chan at WA School of Mines: Minerals, Energy and Chemical Engineering, Curtin University.

Cano, A., Fortunati, E., Chafer, M., Kenny, J. M., Chiralt, A., and GonzalezMartínez, C. (2015c). Properties and ageing behaviour of pea starch films as affected by blend with poly(vinyl alcohol). Food Hydrocoll. 48, 84-93. doi: 10.1016/j.foodhyd.2015.01.008

Cano, A. I., Cháfer, M., Chiralt, A., and González-Martínez, C. A. (2015a). Physical and microstructural properties of biodegradable films based on pea starch and PVA. J. Food Eng. 167, 59-64. doi: 10.1016/j.jfoodeng.2015. 06.003

Castro-Aguirre, E., Auras, R., Selke, S., Rubino, M., and Marsh, T. (2018). Impact of nanoclays on the biodegradation of poly(lactic acid) nanocomposites. Polymers 10:202. doi: 10.3390/polym10020202

Chow, W. S., Tham, W. L., Poh, B. T., and Mohd Ishak, Z. A. (2018) Mechanical and thermal oxidation behavior of poly(lactic acid)/halloysite nanotube nanocomposites containing $\mathrm{N}, \mathrm{N}^{\prime}$-ethylenebis(Stearamide) and SEBS-g-MA. J. Polym. Environ. 26, 2973-2982. doi: 10.1007/s10924-0181186-7

Dong, Y., Marshall, J., Haroosh, H. J., Mohammadzadehmoghadam, S., Liu, D., Qi, X., et al. (2015). Polylactic acid (PLA)/halloysite nanotube (HNT) composite mats: influence of HNT content and modification. Compos. Part A Appl. Sci. Manuf. 76, 28-36. doi: 10.1016/j.compositesa.2015.05.011

Echegoyen, Y., Rodriguez, S., and Nerin, C. (2016). Nanoclay migration from food packaging materials. Food Addit. Contam. Part A Chem. Anal. Control Expo. Risk Assess. 33, 530-539. doi: 10.1080/19440049.2015.1136844

European Union Commission Regulation (EU) No. 10 (2011). Commission regulation on plastic materials and articles intended to come into contact with food. Offic. J. Eur. Un. L 12, 1-89.

Farhoodi, M., Mousavi, S. M., Sotudeh-Gharebagh, R., Emam-Djomeh, Z., and Oromiehie, A. (2014). Migration of aluminum and silicon from pet/clay nanocomposite bottles into acidic food simulant. Packag. Technol. Sci. 27, 161-168. doi: 10.1002/pts.2017

Fizir, M., Dramou, P., Dahiru, N. S., Ruya, W., Huang, T., and He, H. (2018). Halloysite nanotubes in analytical sciences and in drug delivery: a review. Mikrochim. Acta 185:389. doi: 10.1007/s00604-018-2908-1

Follain, N., Joly, C., Dole, P., and Bliard, C. (2005). Properties of starch based blends. Part 2. Influence of poly vinyl alcohol addition and photocrosslinking on starch based materials mechanical properties. Carbohyd. Polym. 60, 185-192. doi: 10.1016/j.carbpol.2004.12.003

Fortunati, E., Peltzer, M., Armentano, I., Torre, L., Jimenez, A., and Kenny, J. M. (2012). Effects of modified cellulose nanocrystals on the barrier and migration properties of PLA nano-biocomposites. Carbohyd. Polym. 90, 948-956. doi: 10.1016/j.carbpol.2012.06.025

Fujii, K., Nakagaito, A. N., Takagi, H., and Yonekura, D. (2014). Sulfuric acid treatment of halloysite nanoclay to improve the mechanical properties of PVA/halloysite transparent composite films. Compos. Interf. 21, 319-327. doi: 10.1080/15685543.2014.876307

Gaaz, T. S., Sulong, A. B., Akhtar, M. N., Kadhum, A. A., Mohamad, A. B., and Al-Amiery, A. A. (2015). Properties and applications of polyvinyl alcohol, halloysite nanotubes and their nanocomposites. Molecules 20, 22833-22847. doi: 10.3390/molecules201219884

Gaaz, T. S., Sulong, A. B., Kadhum, A. A. H., Al-Amiery, A. A., Nassir, M. H., and Jaaz, A. H. (2017). The impact of halloysite on the thermo-mechanical properties of polymer composites. Molecules. 22:E838. doi: 10.3390/molecules22050838

Geyer, R., Jambeck, J. R., and Law, K. L. (2017). Production, use, and fate of all plastics ever made. Sci. Adv. 3:e1700782. doi: 10.1126/sciadv.1700782

Gressler, S., Part, F., Gazsó, A., and Huber-Humer, M. (2018). Nanotechnological applications for food contact materials. Nano. Trust. Dosseirs. Nr. 49, 1-6. doi: 10.1553/ita-nt-049en 
Grunlan, J. C., Grigorian, A., Hamilton, C. B., and Mehrabi, A. R. (2003). Effect of clay concentration on the oxygen permeability and optical properties of a modified poly(vinyl alcohol). J. Appl. Polym. Sci. 93, 1102-1109. doi: 10.1002/app.20564

Guimarães, M. Jr., Botaro, V. R., Novack, K. M., Teixeira, F. G., and Tonoli, G. H. D., (2015). Starch/PVA-based nanocomposites reinforced with bamboo nanofibrils. Ind. Crop. Prod. 70, 72-83. doi: 10.1016/j.indcrop.2015.03.014

Guo, M., Wang, A., Muhammad, F., Qi, W., Ren, H., and Zhu Guo, G. (2012). Halloysite nanotubes, a multifunctional nanovehicle for anticancer drug delivery. Chinese J. Chem. 30, 2115-2120. doi: 10.1002/cjoc.201200657

Guohua, Z., Ya, L., Cuilan, F., Min, Z., Caiqiong, Z., and Zongdao, C. (2006). Water resistance, mechanical properties and biodegradability of methylatedcornstarch/poly(vinyl alcohol) blend film. Polym. Degrad. Stab. 91, 703-711. doi: 10.1016/j.polymdegradstab.2005.06.008

Gupta, B., Agarwal, R., and Alam, M. S. (2013). Preparation and characterization of polyvinyl alcohol-polyethylene oxide-carboxymethyl cellulose blend membranes. J. Appl. Polym. Sci. 127, 1301-1308. doi: 10.1002/app.37665

Hannon, J. C., Kerry, J. P., Cruz-Romero, M., Azlin-Hasim, S., Morris, M., and Cummins, E. (2016). Assessment of the migration potential of nanosilver from nanoparticle-coated low-density polyethylene food packaging into food simulants. Food Addit. Contam. Part A Chem. Anal. Control Expo. Risk Assess. 33, 167-178. doi: 10.1080/19440049.2015.1114184

He, Y., Kong, W., Wang, W., Liu, T., Liu, Y., Gong, Q., et al. (2012). Modified natural halloysite/potato starch composite films. Carbohyd. Polym. 87, 2706-2711. doi: 10.1016/j.carbpol.2011.11.057

Heidarian, P., Behzad, T., and Sadeghi, M. (2017). Investigation of cross-linked PVA/starch biocomposites reinforced by cellulose nanofibrils isolated from aspen wood sawdust. Cellulose. 24, 3323-3339. doi: 10.1007/s10570-017-1336-4

Hejri, Z., Seifkordi, A. A., Ahmadpour, A., Zebarjad, S. M., and Maskooki, A. (2013). Biodegradable starch/poly (vinyl alcohol) film reinforced with titanium dioxide nanoparticles. Int. J. Miner. Metall. Mater. 20, 1001-1011. doi: 10.1007/s12613-013-0827-Z

Huang, Y., Chen, S., Bing, X., Gao, C., Wang, T., and Yuan, B. (2011). Nanosilver migrated into food-simulating solutions from commercially available food fresh containers. Packag. Technol. Sci. 24, 291-297. doi: 10.1002/pts.938

Imam, S. H., Cinelli, P., Gordon, S. H., and Chiellini, E. (2005). Characterization of biodegradable composite films prepared from blends of poly(vinyl alcohol), cornstarch, and lignocellulosic fiber. J. Polym. Environ. 13, 47-55. doi: 10.1007/s10924-004-1215-6

Ismail, H., and Zaaba, N. F. (2011). Effect of additives on properties of polyvinyl alcohol (PVA)/Tapioca starch biodegradable films. Polym. Plast. Technol. Eng. 50, 1214-1219. doi: 10.1080/03602559.2011.566241

Jayasekara, R., Harding, I., Bowater, I., ,Christie, G. B. Y., and Lonergan, G. T. (2003). Biodegradation by composting of surface modified starch and PVA blended films. J. Polym. Environ. 11, 49-56. doi: 10.1023/A:1024219821633

Jolanta, W. K., Rydzkowski, T., Borowski, G., Szczypinski, M., Klepka, T., and Thakur, V. K. (2018). Recent progress in biodegradable polymers and nanocomposite-based packaging materials for sustainable environment. Int. J. Polym. Anal. Charact. 23, 383-395. doi: 10.1080/1023666X.2018.1455382

Kale, G., Kijchavengkul, T., Auras, R., Rubino, M., Selke, S. E., and Singh, S. P. (2007). Compostability of bioplastic packaging materials: an overview. Macromol. Biosci. 7, 255-277. doi: 10.1002/mabi.200600168

Kamble, R., Ghag, M., Gaikawad, S., and Panda, B. K. (2012). Halloysite nanotubes and applications: a review. J. Adv. Sci. Res. 3, 25-29.

Khoo, W. S., Ismail, H., and Ariffin, A. (2011). Tensile and Swelling Properties of Polyvinyl alcohol/Chitosan/Halloysite Nanotubes Nanocomposite. Kuala Lumpur: 2011 National Postgraduate Conference. doi: 10.1109/natpc.2011.6136541

Kisku, S. K., Sarkar, N., Dash, S., and Swain, S. K. (2014). Preparation of starch/PVA/ $\mathrm{CaCO}_{3}$ nanobiocomposite films: study of fire retardant, thermal resistant, gas barrier and biodegradable properties. Polym. Plast. Technol. Eng. 53, 1664-1670. doi: 10.1080/03602559.2014.919650

Kopcilova, M., Hubackova, J., Ruzicka, J., Dvorackova, M., Julinova, M., Koutny, M., et al. (2013). Biodegradability and mechanical properties of poly(vinyl alcohol)-based blend plastics prepared through extrusion method. J. Polym. Environ. 21, 88-94. doi: 10.1007/s10924-012-0520-8

Kryuchkova, M., Danilushkina, A., Lvov, Y., and Fakhrullin, R. (2016). Evaluation of toxicity of nanoclays and graphene oxide in vivo: a
Paramecium caudatum study. Environ. Sci. Nano. 3, 442-452. doi: 10.1039/c5en $00201 j$

Kubiak, K. J., Wilson, M. C. T., Mathia, T. G., and Carval, P. (2011). Wettability versus roughness of engineering surfaces. Wear. 271, 523-528. doi: 10.1016/j.wear.2010.03.029

Lee, M. H., Kim, S. Y., and Park, H. J. (2018). Effect of halloysite nanoclay on the physical, mechanical, and antioxidant properties of chitosan films incorporated with clove essential oil. Food Hydrocolloid. 84, 58-67. doi: 10.1016/j.foodhyd.2018.05.048

Lim, M., Kwon, H., Kim, D., Seo, J., Han, H., and Khan, S. B. (2015). Highly-enhanced water resistant and oxygen barrier propertiesof cross-linked poly(vinyl alcohol) hybrid filmsfor packaging applications. Prog. Org. Coat. 85, 68-75. doi: 10.1016/j.porgcoat.2015.03.005

Liu, M., Guo, B., Du, M., and Jia, D. (2007). Drying induced aggregation of halloysite nanotubes in polyvinyl alcohol/halloysite nanotubes solution and its effect on properties of composite film. Appl. Phys. A. 88, 391-395. doi: 10.1007/s00339-007-3995-8

Liu, M., Jia, Z., Jia, D., and Zhou, C. (2014). Recent advance in research on halloysite nanotubes-polymernanocomposite. Prog. Polym. Sci. 93, 1498-1525. doi: 10.1016/j.progpolymsci.2014.04.004

Liu, Z., Feng, Y., and Yi, X. (1999). Thermoplastic starch/PVAl compounds: preparation, processing, and properties. J. Appl. Polym. Sci. 74, 2667-2673. doi: 10.1002/(SICI)1097-4628(19991209)74:11<2667::AID-APP14>3.0.CO;2-D

Luo, X., Li, J., and Lin, X. (2012). Effect of gelatinization and additives on morphology and thermal behavior of corn starch/PVA blend films. Carbohyd. Polym. 90, 1595-1600. doi: 10.1016/j.carbpol.2012.07.036

Lvov, Y. M., DeVilliers, M. M., and Fakhrullin, R. F. (2016). The application of halloysite tubule nanoclay in drug delivery. Expert Opin. Drug Deliv. 13, 977-986. doi: 10.1517/17425247.2016.1169271

Magnier, L., and Crié, D. (2015). Communicating packaging eco-friendliness. J. Ret. Distribut. Manag. 43, 350-366. doi: 10.1108/ijrdm-04-2014-0048

Makaremi, M., Pasbakhsh, P., Cavallaro, G., Giuseppe Lazzara, G., Aw, Y. K., Lee, S. M., et al. (2017). Effect of morphology and size of halloysite nanotubes on functional pectin bionanocomposites for food packaging applications. ACS Appl. Mater. Interfaces 9, 17476-17488. doi: 10.1021/acsami.7b04297

Mauricio-Iglesias, M., Peyron, S., Guillard, V., and Gontard, N. (2010). Wheat gluten nanocomposite films as food-contact materials: migration tests and impact of a novel food stabilization technology (high pressure). J. Appl. Polym. Sci. 116, 2526-2535. doi: 10.1002/app.31647

Mensitieri, G., Di Maio, E., Buonocore, G. G., Nedi, I., Oliviero, M., Sansone, L., et al. (2011). Processing and shelf life issues of selected food packaging materials and structures from renewable resources. Trends. Food. Sci. Technol. 22, 72-80. doi: 10.1016/j.tifs.2010.10.001

Negim, E. S. M., Rakhmetullayeva, R. K., Yeligbayeva, G. Z., Urkimbaeva, P. I., Primzharova, S. T., Kaldybekov, D. B., et al. (2014). Improving biodegradability of polyvinyl alcohol/starch blend films for packaging applications. Int. J. Basic. Appl. Sci. 3, 263-273. doi: 10.14419/ijbas.v3i3.2842

Noshirvani, N., Ghanbarzadeh, B., Fasihi, H., and Almasi, H. (2016). StarchPVA nanocomposite film incorporated with cellulose nanocrystals and $\mathrm{mmt}$ a comparative study. Int. J. Food. Eng. 12, 37-48. doi: 10.1515/ijfe-2015-0145

Qiu, K., and Netravali, A. N. (2013). Halloysite nanotube reinforced biodegradable nanocomposites using noncrosslinked and malonic acid crosslinked polyvinyl alcohol. Polym. Compos. 34, 799-809. doi: 10.1002/pc.22482

Qiu, K., and Netravali, A. N. (2015). "Polyvinyl alcohol based biodegradable polymer nanocomposites," in Biodegradable Polymers, eds C. C. Chu (New York, NY: Nova Science Publishers, Inc), 326-379.

Rahman, W. A. W. A., Sin, L. T., Rahmat, A. R., and Samad, A. A. (2010). Thermal behaviour and interactions of cassava starch filled with glycerol plasticized polyvinyl alcohol blends. Carbohyd. Polym. 81, 805-810. doi: 10.1016/j.carbpol.2010.03.052

Rawtani, D., and Agrewal, Y. K. (2012). Multifarious applications of halloysite nanotubes: a review. Rev. Adv. Mater. Sci. 30, 282-295.

Ray, S. S., and Bousmina, M. (2005). Biodegradable polymers and their layered silicate nanocomposites: In greening the 21st century materials world. Prog. Mater. Sci. 50, 962-1079. doi: 10.1016/j.pmatsci.2005. 05.002

Ren, J., Dang, K., Pollet, E., and Avérous, L. (2018). Preparation and Characterization of thermoplastic potato starch/halloysite 
nano-biocomposites: effect of plasticizer nature and nanoclay content. Polymers 10:808. doi: 10.3390/polym10080808

Sadegh-Hassani, F., and Nafchi, A. M. (2014). Preparation and characterization of bionanocomposite films based onpotato starch/halloysite nanoclay. Int. J. Biol. Macromol. 67, 458-462. doi: 10.1016/j.ijbiomac.2014.04.009

Salam, H., Dong, Y., and Davies, I. (2015). "Development of biobased polymer/clay nanocomposites," in Fillers and Reinforcements for Advanced Nanocomposites, eds Y. Dong, R. Umer, and A. Lau (Cambridge: Elsevier), 101-132.

Salleh, M. S. N., Mohamed Nor, N. N., Mohd, N., and Syed Draman, S. F. (2017). Water resistance and thermal properties of polyvinyl alcohol-starch fiber blend film. AIP Conf. Proc. 1809:020045. doi: 10.1063/1.4975460

Sam, S. T., Nuradibah, M. A., Chin, K. M., and Hani, N. (2016). "Current application and challenges on packaging industry based on natural polymer blending," in Natural Polymers-Industry Technques and Applications, ed O. Olatunji (London: Springer), 163-184.

Sang, K., Hori, Y., Tanji, H., and Unno, B. I. (2002). Fungal contribution to in situ biodegradation of poly(3-hydroxybutyrate- co-3-hydroxyvalerate) film in soil. Appl. Microbiol. Biotechnol. 58, 241-247. doi: 10.1007/s00253-001-0884-5

Santos, A. C., Ferreira, C., Veiga, F., Ribeiro, A. J., Panchal, A., Lvov, Y., et al. (2018). Halloysite clay nanotubes for life sciences applications: from drug encapsulation to bioscaffold. Adv. Colloid Interface Sci. 257, 58-70. doi: 10.1016/j.cis.2018.05.007

Schmidt, B., Petersen, J. H., Bender Koch, C., Plackett, D., Johansen, N. R., Katiyar, V., et al. (2009). Combining asymmetrical flow field-flow fractionation with light-scattering and inductively coupled plasma mass spectrometric detection for characterization of nanoclay used in biopolymer nanocomposites. Food Addit. Contam. Part A Chem. Anal. Control Expo. Risk Assess. 26, 1619-1627. doi: $10.1080 / 02652030903225740$

Schmitt, H., Creton, N., Prashantha, K., Soulestin, J., Lacrampe, M. F., and Krawczak, P. (2015). Preparation and characterization of plasticized starch/halloysite porous nanocomposites possibly suitable for biomedical applications. J. Appl. Polym. Sci. 132:41341. doi: 10.1002/app.41341

Shah, A. A., Hasan, F., Hameed, A., and Ahmed, S. (2008). Biological degradation of plastics: a comprehensive review. Biotechnol. Adv. 26, 246-265. doi: 10.1016/j.biotechadv.2007.12.005

Simon, P., Chaudhry, Q., and Bakos, D. (2008). Migration of engineered nanoparticles from polymer packaging to food - a physicochemical view. $J$. Food. Nutr. Res. 47, 105-113.

Singha, A. S., and Kapoor, H. (2014). Effects of plasticizer/cross-linker on the mechanical and thermal properties of starch/PVA blends. Iran. Polym. J. 23, 655-662. doi: 10.1007/s13726-014-0260-9

Siracusa, V., Rocculi, P., Romani, S.a., and Rosa, M. D. (2008). Biodegradable polymers for food packaging: a review. Trends. Food. Sci. Technol. 19, 634-643. doi: 10.1016/j.tifs.2008.07.003

Sorrentino, A., Gorrasi, G., and Vittoria V. (2007). Potential perspectives of bionanocomposites for food packaging applications. Trends. Food. Sci. Technol. 18, 84-95. doi: 10.1016/j.tifs.2006.09.004

Sustainable Packaging Coalition. (2011). Definition-of-Sustainable-Packaging. Available online at: https://sustainablepackaging.org/wp-content/uploads/ 2017/09/Definition-of-Sustainable-Packaging.pdf (Accessed 1 October, 2011).

Swapna, V. P., Thomas, P. S., Suresh, K. I., Saranya, V., Rahana, M. P., and Stephen, R. (2015). Thermal properties of poly (vinyl alcohol)(PVA)/halloysite nanotubes reinforced nanocomposites. Int. J. Plast. Technol. 19, 124-136. doi: $10.1007 /$ s12588-015-9106-3

Taghizdeh, M. T., Abbasi, Z., and Nasrollahzade, Z. (2012). Study of enzymatic degradation and water absorption of nanocomposites starch/polyvinyl alcohol and sodium montmorillonite clay. J. Taiwan. Inst. Chem. Eng. 43, 120-124. doi: 10.1016/j.jtice.2011.07.006

Talja, R. A., Helen, H., Roos, Y. H., and Jouppila, K. (2007). Effect of various polyols and polyol contents on physical and mechanical properties of potato starchbased films. Carbohyd. Polym. 67, 288-295. doi: 10.1016/j.carbpol.2006.05.019

Tanase, E. E., Popa, M. E., Rapa, M., and Popa, O. (2015). Preparation and characterization of biopolymer blends based on polyvinyl alcohol and starch. Roman. Biotechnol. Lett. 20, 10306-10315.

Tang, S., Zou, P., Xiong, H., and Tang, H. (2008). Effect of nano- $\mathrm{SiO}_{2}$ on the performance of starch/polyvinyl alcohol blend films. Carbohyd. Polym. 72, 521-526. doi: 10.1016/j.carbpol.2007.09.019
Tang, X., and Alavi, S. (2011). Recent advances in starch, polyvinyl alcohol based polymer blends, nanocomposites and their biodegradability. Carbohyd. Polym. 85, 7-16. doi: 10.1016/j.carbpol.2011.01.030

Thakore, I. M., Desai, S., Sarawade, B. D., and Devi, S. (2001). Studies on biodegradability, morphology and thermomechanical properties of LDPE/modifed starch blends. Eur. Polym. J. 37, 151-160. doi: 10.1016/S0014-3057(00)00086-0

The European Standard EN. (2002). Materials and articles in contact with foodstuffs -plastics-part 1: guide to the selection of conditions and test methods for overall migration. Eur. Committ. Stand.1-52

Tian, H., Wang, K., Liu, D., Yan, J., Xiang, A., and Varada Rajulu, A. (2017). Enhanced mechanical and thermal properties of poly (vinylalcohol)/corn starch blends by nanoclay intercalation. Int. J. Biol. Macromol. 101, 314-320. doi: 10.1016/j.ijbiomac.2017.03.111

Tully, J., Fakhrullin, R., and Lvov, Y. (2015). "Halloysite clay nanotube composites with sustained release of chemicals," in Nanomaterials and Nanoarchitectures, eds M. Bardosova and T. Wagner (Dordrecht: Springer), 87-118.

Velichkova, H., Petrova, I., Kotsilkov, S., Ivanov, E., Vitanov, N. K., and Kotsilkova, R. (2017). Influence of polymer swelling and dissolution into food simulants on the release of graphene nanoplates and carbon nanotubes from poly(lactic) acid and polypropylene composite films. J. Appl. Polym. Sci. 134:45469. doi: 10.1002/app.45469

Vergaro, V., Abdullayev, E., Lvov, Y. M., Zeitoun, A. R., Cingolani, R., and Leporatti, S. (2010). Cytocompatibility and uptake of halloysite clay nanotubes. Biomacromolecules 11, 820-826. doi: 10.1021/bm9014446

Wang, W., Zhang, H., Dai, Y., Hou, H., and Dong, H. (2015). Effects of low poly(vinyl alcohol) content on properties of biodegradable blowing films based on two modified starches. J. Thermoplast. Compos. Mater. 30, 1017-1030. doi: $10.1177 / 0892705715614080$

Wenzel, R. N. (1949).Surface roughness and contact angle. J. Phys. Chem. 53, 1466-1467. doi: 10.1021/j150474a015

Xie, Y., Chang, P. R., Wang, S., Yu, J., and Ma, X. (2011). Preparation and properties of halloysite nanotubes/plasticized dioscorea opposita thunb. Starch composites. Carbohyd. Polym. 83, 186-191. doi: 10.1016/j.carbpol.2010. 07.039

Yuan, P., Tan, D., and Faïza, A. B. (2015). Properties and applications of halloysite nanotubes: recent research advances and future prospects. Appl. Clay Sci. 112-113, 75-93. doi: 10.1016/j.clay.2015.05.001

Yuan, Y., and Lee, T. R. (2013). "Contact angle and wetting properties" in Surface Science Techniques, eds G. Bracco and B. Holst (Berlin: Verlag Berlin Heidelberg; Springer), 3-34.

Zanela, J., Olivato, J. B., Dias, A. P., Grossmann, M. V. E., and Yamashita, F. (2015). Mixture design applied for the development of films based on starch, polyvinyl alcohol, and glycerol. J. Appl. Polym. Sci. 132:42697. doi: 10.1002/app. 42697

Zhang, Y., Tang, A., Yung, H., and Ouyang, J. (2016). Applications and interfaces of halloysite nanocomposites. Appl. Clay Sci. 119, 8-17. doi: 10.1016/j.clay.2015.06.034

Zhou, W. Y., Guo, B., Liu, M., Liao, R., Rabie, A. B., and Jia, D. (2010). Poly(vinyl alcohol)/halloysite nanotubes bionanocomposite films: properties and in vitro osteoblasts and fibroblasts response. J. Biomed. Mater. Res. A. 93, 1574-1587. doi: 10.1002/jbm.a.32656

Zou, G. X., Ping-Qu, J., and Liang-Zou, X. (2008). Extruded starch/PVA composites: water resistance, thermal properties, and morphology. J. Elastom. Plast. 40, 303-316. doi: 10.1177/0095244307085787

Conflict of Interest Statement: The authors declare that the research was conducted in the absence of any commercial or financial relationships that could be construed as a potential conflict of interest.

Copyright (c) 2019 Abdullah and Dong. This is an open-access article distributed under the terms of the Creative Commons Attribution License (CC BY). The use, distribution or reproduction in other forums is permitted, provided the original author(s) and the copyright owner(s) are credited and that the original publication in this journal is cited, in accordance with accepted academic practice. No use, distribution or reproduction is permitted which does not comply with these terms. 